NBER WORKING PAPER SERIES

\title{
CAN FINANCIAL INCENTIVES REDUCE THE BABY GAP? EVIDENCE FROM A REFORM IN MATERNITY LEAVE BENEFITS
}

\author{
Anna Raute \\ Working Paper 23793 \\ http://www.nber.org/papers/w23793 \\ NATIONAL BUREAU OF ECONOMIC RESEARCH \\ 1050 Massachusetts Avenue \\ Cambridge, MA 02138 \\ September 2017
}

I am grateful to Christian Dustmann and Uta Schönberg for their support on this project. I also want to thank Andreas Lichter, Claudia Olivetti, Jim Poterba, Andrea Weber and many conference and seminar participants at Trans-Atlantic Public Economics Seminar 2016, Harvard Kennedy School, Cosme Gender Economics Workshop 2016, American Economic Association Meetings 2016, University of Oslo, SOFI Stockholm, NHH Bergen, University College London, Royal Holloway and others for helpful comments. I want to thank Dirk Mai and Tatjana Mika from the Research Data Centre of the German Federal Pension Insurance (FDZ-RV) for their support with the Pension Registry data and Tom Wey for his assistance with programming the benefit-schedules. I am also grateful to the data services of the IDSC of IZA. Financial support from the German National Academic Foundation and the Centre for Research and Analysis of Migration is gratefully acknowledged. All errors are my own. The views expressed herein are those of the author and do not necessarily reflect the views of the National Bureau of Economic Research.

NBER working papers are circulated for discussion and comment purposes. They have not been peer-reviewed or been subject to the review by the NBER Board of Directors that accompanies official NBER publications.

(C) 2017 by Anna Raute. All rights reserved. Short sections of text, not to exceed two paragraphs, may be quoted without explicit permission provided that full credit, including $\odot$ notice, is given to the source. 
Can Financial Incentives Reduce the Baby Gap? Evidence from a Reform in Maternity Leave Benefits

Anna Raute

NBER Working Paper No. 23793

September 2017

JEL No. J13,J16,J18

\begin{abstract}
To assess whether earnings-dependent maternity leave positively impacts fertility and narrows the baby gap between high educated (high earning) and low educated (low earning) women, I exploit a major maternity leave benefit reform in Germany that considerably increases the financial incentives for higher educated and higher earning women to have a child. In particular, I use the large differential changes in maternity leave benefits across education and income groups to estimate the effects on fertility up to 5 years post reform. In addition to demonstrating an up to $22 \%$ increase in the fertility of tertiary educated versus low educated women, I find a positive, statistically significant effect of increased benefits on fertility, driven mainly by women at the middle and upper end of the education and income distributions. Overall, the results suggest that earnings-dependent maternity leave benefits, which compensate women commensurate with their opportunity cost of childbearing, could successfully reduce the fertility rate disparity related to mothers' education and earnings.
\end{abstract}

\author{
Anna Raute \\ Department of Economics \\ University of Mannheim \\ L7, 3-5 \\ 68131 Mannheim, Germany \\ a.raute@uni-mannheim.de
}




\section{Introduction}

As women's educational attainment and labor market participation have increased, so too have concerns about decreasing birth rates and below replacement fertility levels. Among developed countries, Germany, Italy, South Korea, and Japan are all experiencing total fertility rates between 1.3 and 1.4, and even the U.S. has seen its traditionally high fertility fall to a record low well under replacement level (Table 1, Panel A).

In an attempt to mitigate this decrease, all OECD countries except the U.S. now ensure paid maternity leave, 1 which provides employment protection and some degree of earnings replacement, with a primary goal of facilitating family and career compatibility and improving child welfare. Another aim of such policies, one that has received far less research attention, however, is to encourage fertility by reducing the opportunity costs of childbearing. For example, according to German Chancellor Angela Merkel, the low fertility rate among highly educated women was a motivating force behind the 2007 German reform studied here, which represents a "paradigm shift in social policy" (Bundesregierung (2006)) . $^{2}$

In addition to this decrease in overall birth rates (Table 1, Panel B), in many developed countries, highly educated and high earning women are also having fewer children over a lifetime than their lower educated and lower earning peers, a competed fertility differential that I label the "baby gap." The likeliest explanation for this negative relation between education and completed fertility is the higher opportunity costs of childbearing for the more highly educated, who must forego a higher wage to temporarily leave the labor market (Willis (1973)) $t^{3}$ In Germany, this gap manifests as a stark difference between highly and lower educated women in both number of children borne (1.33 vs. 2.06) and the percentage of childless women. In fact, nearly one-third of the 1963-1967 cohort of highly educated women in Germany have never had a child, compared to $18 \%$ of women with no postsecondary schooling. Likewise, in the U.S., women with a college degree born in 1965-1969 gave birth to an average of 1.81 children compared with 2.56 for women in the same cohort who did not complete high school. In countries with traditionally generous family policies, however (e.g., Sweden), the disparities between education groups are smaller.

In this paper, therefore, I examine whether paid maternity leave does in fact affect

\footnotetext{
${ }^{1}$ Because my entire analysis focuses on the effect on mothers, I refer to the benefit as "maternity leave" rather than using the umbrella term "parental leave," which encompasses maternal, paternal, and adoption leave (and sometimes even family leave for other types of care).

2"Support of families used to be support of families in need. (...). We face the problem, that $40 \%$ of tertiary educated do not have children. A country, which calls itself highly developed, can not afford such a situation." (Bundesregierung (2006)).

${ }^{3}$ See also Aaronson et al. (2014) for recent empirical evidence. As predicted by theory, fertility has been shown to decrease with a woman's potential wage (see e.g. Rosenzweig and Schultz (1985) and Heckman and Walker (1990)).
} 
fertility decisions by exploiting a 2007 maternity leave reform in Germany that substantially changed maternal compensation for time out of the labor market following childbirth. Before this reform, German maternity leave benefits were flat means tested transfers targeted at lower income families that paid an average benefit of around 4,000 EUR for a maximum of two years irrespective of the mother's pre birth earnings. Since 2007, however, the new scheme has offered mothers a generous income replacement of at least $67 \%$ of annual pre birth earnings, with a maximum 3,600 EUR basic transfer for women not in the workforce pre partum. Nonetheless, although the reform means a benefit increase of up to 21,000 EUR for more highly educated and higher earning women, the changes for very low earning (and lower educated) women are modest or even negative.

To measure the extent to which fertility in Germany has reacted to this reform and add valuable new insights to the currently sparse empirical evidence on this effect, I apply a differences-in-differences approach exploiting the differential changes in leave benefits across several earnings and education groups. As my primary data set, I use novel administrative data from the German Pension Registry, which records precise information on earnings, education, and fertility for all women insured under the statutory pension insurance scheme. I complement this information with data from the nationally representative German Microcensus, which employs rich demographic measures.

If earnings-related paid leave affects women's fertility decisions, then I should observe those who benefit most to increase fertility relative to their peers who benefit less. My empirical analysis does indeed uncover substantial pronatal effects of the reform, as well as medium run changes in the socioeconomic structure of fertility, a finding that matters not only for countries with low fertility rates, but also for governments trying to mitigate the declining fertility associated with women's increased labor market participation. First, based on vital statistics, I document discontinuous jumps in monthly birth rates of close to $4 \%$ nine months after reform implementation, which translates into 2.350 additional children each year born in the short term and an increasing trend in birth rates post discontinuity. Second, by exploiting the large differential changes in maternity benefits across income and education groups, I demonstrate that the probability of having a child in a given year within the five year post reform period increases by up to 1.1 percentage points (22\%) for highly educated relative to low educated women. At the same time, the medium term (within five year) fertility of women earning above the median, who benefit substantially from the reform, increases by $18 \%$ as a result of the paid leave changes. In fact, the reform appears to be positively affecting the fertility of women in all earnings groups beyond the median, including the top 5th percentile, although admittedly, these intention-to-treat effects on fertility be- 
havior, being policy relevant parameters, could be driven by both increased monetary transfers and any endogenous labor supply adjustments. Third, under the assumption that the post reform changes in paid maternity leave only affect fertility by increasing the financial incentives to have a child, I can use the reform to estimate the changes in financial incentives on fertility. My baseline estimate suggests that a 1,000 EUR increase in total potential entitlement raises the birth probability by 0.78 percentage points $(2.1 \%)$ in each year post reform. Lastly, by estimating the effect of the reform separately for different age groups, I find a strong reform-induced increase in fertility for women aged 35-39 and 40-44, who are nearing the end of their lifetime fertility and unlikely to postpone childbearing, Such an increase in these cohorts' medium run fertility is likely to have a permanent effect and raise their completed fertility.

My findings contribute to a growing body of literature on family policies and fertility, which, in estimating financial incentives' effect on fertility, faces the major methodological challenge of getting exogenous variation in the cost of fertility (see Hotz et al. (1997)). ${ }^{4}$ Similar difficulties present in numerous studies in the large structural literature on how financial incentives impact women's lifecycle fertility and labor supply (e.g. Moffitt (1984), Keane and Wolpin (2010), Laroque and Salanié (2014) and Adda et al. (2017)). Among these latter studies on lifecycle fertility, Heckman and Walker (1990) find female wages to become an increasingly less accurate measure of the price of fertility for more recent Swedish cohorts and argue that the finding might result from the introduction of Swedish family policies, which lowered the cost of child care and offset the increasing cost of women's time for these cohorts.5

Another major investigative stream in the field is the quasi-experimental literature, which tends to focus on the incentive effect of child subsidies, child cash transfers, and welfare programs, all designed to set higher financial incentives for lower income women ${ }^{6}$ Two such studies, which exploit the variation in universal child subsidies for the third (or higher child) relative to the first or second child in Quebec (Milligan (2005)) and Israel (Cohen et al. (2013)) find a strong pronatal effect of these policies. Another investigation of the German context (Riphahn and Wynck (2017)) assesses the effects

\footnotetext{
${ }^{4}$ As government family policy which provides financial and in-kind support for families with children is usually universal, it sets financial incentives to all women and does not provide a natural control group for the counterfactual situation. Many early studies were relying on time series variation, such as Whittington et al. (1990) who analyze responses of fertility to the personal tax exemption in the US.

${ }^{5}$ They note that they fail to directly estimate the policy effect due to the inability to define precise measures of policy (see footnote 10 in Heckman and Walker (1990)).

${ }^{6}$ See for instance, the paper by González (2013) on the positive immediate fertility effects of an introduction of a universal cash benefit in Spain. Moffitt (1998) provides an overview of the literature on the effects of AFDC and concludes that the evidence is inconclusive. Baughman and Dickert-Conlin (2003) and Brewer et al. (2011) find positive effects on the fertility of low-income women for increases in the EITC and the effect of UK welfare reforms respectively.
} 
of a child benefit reform that combines cash benefits and tax deductions while raising the transfer differential dependent on household income and number of children. In this study, first births in low income households show no response to increased transfers, although the transfers do have modest positive effects for second-order births among highly educated women relative to low educated women.

The literature on paid maternity leave, in contrast, focuses largely on the programs' effects on maternal labor supply and child outcomes (see particularly Baker and Milligan (2008, 2010), Dustmann and Schönberg (2012) and Carneiro et al. (2014)), although evidence on the impact on fertility is still sparse, with little consensus across studies.7 One seminal investigation by Lalive and Zweimüller (2009) does identify strong effects of an Austrian expansion in the duration of paid job-protected maternity leave for a first child on the mother's (subsequent) higher order fertility. However, because the maternity leave benefits are flat payments independent of pre birth earnings, the extension of the leave duration inherently affects higher order fertility more strongly for low wage mothers than for high wage mothers. An analysis of the long run effects of a series of expansions in paid maternity leave in Norway, however, finds little effect on completed fertility (Dahl et al. $(2016)$ ); however, these authors do not run their assessments across different socioeconomic groups. Both Cygan-Rehm (2015) and Kluve and Schmitz (forthcoming) analyze the effect of the German paid leave reform on higherorder births. Cygan-Rehm 2015) identifies an extension of higher order birth spacing up to 5 years post reform that is driven by low income mothers, who the reform does not benefit. All other income groups have seemingly caught up with the initial fertility delay after the third year, although Kluve and Schmitz (forthcoming) also identify negative effects on subsequent childbearing up to 5 years after the first birth, driven by young and lower-income women. All these studies adopt a regression discontinuity design that compares the subsequent fertility of mothers who gave birth to their current child immediately before and after the paid maternity leave reform, meaning different paid leave benefits for the current child but identical benefits for the future child. As a result, they all identify a specific incentive effect for the second (or higher order) birth decision, which they label the "current child effect." These effects on subsequent childbearing have three potential drivers: changes in the benefit level and duration for the current child, a change in the return to work after the birth of the current child, and changes in the automatic renewal periods of benefits for the future child 8

\footnotetext{
${ }^{7}$ In his descriptive analysis, Björklund (2006) examines the evolution of completed fertility patterns for Swedish cohorts who were affected by the large extension of family policies in the 60s and 70s relative to women in neighboring countries. His results suggest that the extension of family policies raised the level of fertility and shortened the spacing of births, but could not fully eliminate the negative relationship between women's educational level and completed fertility.

${ }^{8}$ Both Cygan-Rehm (2015) and Kluve and Schmitz (forthcoming) mention that it is impossible to
} 
My study adds to this literature along several important dimensions. First, the empirical analysis provides causal evidence of how an increase in paid maternity leave for a baby yet to be born, by lowering the immediate costs associated with childbearing, can directly affect fertility decisions, especially medium run decisions, up to 5 years post reform. To derive this evidence, rather than comparing cohorts of mothers facing the same policy for the first child but different leave duration for the future child (the "future child effect" studied by Lalive and Zweimüller (2009)), I exploit the fact that switching from a flat to an earnings-dependent maternity leave system affects higher earning women more than lower earning women. The switch between benefit systems allows me to apply a differences-in-differences design, which is a tighter identification strategy than the across-cohort comparison. Likewise, the direct incentive effect on fertility decisions of a change in paid maternity leave for a future child, because it reduces the cost of care for that child, is a potentially more policy relevant parameter than the indirect effect on (subsequent) higher order births of leave policy changes for a baby already born. Another limitation of the extant research on paid maternity leave (and universal child subsidies) is that it can only identify a fertility effect along the intensive margin of childbearing, which might be driven by women with high preferences for children. I, in contrast, analyze the fertility effect of paid maternity leave programs not only along the intensive margin but also along the extensive margin. This expansion matters because analyzing the effect(s) on the decision to have a first or second child appears to be the crucial margin of interest, particularly for higher educated women, more than half of whom have at most one child during a lifetime.9 My analysis can thus provide a far more complete picture of how financial incentives affect fertility decisions at a time when falling fertility make it crucial to better understand the effects of earnings-dependent leave policies on fertility behavior. My quasi-experimental evidence is especially relevant because, unlike traditional family policies such as child subsidies, the earnings-dependent schemes introduced in numerous countries aim to compensate women for the opportunity costs of childbearing.

The remainder of the article proceeds as follows. The next section explains how the changes in paid maternity leave legislation in Germany came about and describes the mechanisms through which they can affect fertility decisions. Sections 3 and 4 . respectively, describe the empirical strategy and data sets, after which Section 5 presents the main results. Section 6 then briefly discusses the reform effects across age, and Section 7 concludes the paper.

identify the driving channel of the effects on subsequent fertility.

${ }^{9}$ Among highly educated women aged $40-49$ in $2012,29 \%$ remained childless, $24.4 \%$ had one child, $34.2 \%$ two children and only $12.4 \%$ had three or more children (see BIB (2012)). 


\section{Background}

\subsection{The maternity benefit reform}

Government provided maternity leave, which has a long tradition in Germany, has been expanded in a series of reforms since the late 1970s, and since 1992 has granted mothers a maximum 36 months of very generous post birth job protection as well as publicly funded benefits whilst on leave. ${ }^{10}[1$ In 2007, however, the German government implemented a major reform that fundamentally changed the maternity benefit system.

Under the old scheme, "child-rearing money" (Erziehungsgeld) targeted low income families and paid out under one of two options: a maximum of 300 EUR a month for up to 24 months or a short option monthly payment of 450 EUR over 12 months for mothers who wanted to work in the second year after childbirth (see Table 2). Transfers under both options were means tested on family income during benefit receipt, effectively basing them on the spouse's income, not only because most mothers did not choose to work but because eligibility required that they not work over 30 hours a week. In fact, only families earning below a 30,000 EUR net (40,400 EUR gross) income threshold (after several deductibles) were eligible for any benefit payments, which in 2006 accounted for about $74 \%$ of all mothers. ${ }^{12}$ Of the mothers eligible to choose both options, only about 15\% (predominantly East German women) chose the short run payout, for an average 2006 benefit of between 3,850 and 4,440 EUR in total (based on data from from Statistisches Bundesamt (2006)).13

On January 1, 2007, a new leave benefit, "parental money" (Elterngeld), replaced the old scheme, for which all mothers with children born on or after that date are eligible. In contrast to the old means tested benefits based on family income, the new transfer payments are not only more generous but provide universal coverage. Moreover, despite a primary goal of providing parents with the financial means to care for their child during the first year of life, the reform also aims to increase fertility by tying benefits closely to women's net pre birth earnings so as to compensate their opportunity cost of childbearing. This "paradigm shift in family policy" (Bundesregierung $(2006))$ is thus aimed at "preventing income drops after childbirth, (..) enhancing the

\footnotetext{
${ }^{10}$ During the leave period, the firm is not allowed to dismiss the mother and the mother has the right to return to a job that is comparable to the job she held before childbirth.

${ }^{11}$ Since 1986, fathers have been eligible for parental leave, but very few father took any leave, so the program was effectively a maternity leave program.

${ }^{12}$ Benefits were restricted to a duration of six months (total payment of 1,800 EUR) for those with an income threshold exceeding around 21,000 EUR and below 30,000 EUR, which applied to about $14 \%$ of mothers. In 2006 only about $60 \%$ of mothers were eligible for benefit payments for longer than six months.

${ }^{13}$ Maternal labor force participation has traditionally been low in Germany compared to other Western European countries, with only $36 \%$ of mothers with a child below age three working in 2006, which might explain the low share of mothers choosing the short run option.
} 
economic independence of both parents, and allowing a fair compensation of opportunity costs of childbearing" (BMFSFJ (2008)) 14 Nevertheless, being born out of a newly formed (and rather unexpected) coalition between the two largest political parties, the Christian Democrats and Social Democrats, the new scheme was pushed rather hastily through the legislative procedure. Agreement on the main features occurred in May 2006, publication as a draft law in June 2006, and passing of an amended version by parliament and the second chamber between September 2006 and November 2006 15

The new maternity leave benefit replaces about $67 \%$ of previous net labor earnings for up to 12 months after the birth of a child, with benefits calculated on the basis of the average net earnings during the 12 months pre birth. Previously inactive mothers receive a flat minimum of 300 EUR a month, which translates into a total benefit of 3,600 EUR. Lower earning women are granted a higher than $67 \%$ replacement ratio of previous net labor earnings, which is gradually lowered from $100 \%$ to $67 \%$ for women with monthly net earnings between 300 and 1,000 EUR. The transfer is truncated at 1,800 EUR a month, meaning a maximum benefit of 21,600 EUR for women with average net (gross) pre birth monthly (yearly) earnings above 2,700 EUR (around 60,000 EUR). As with the old system, eligibility depends on benefit recipients not working more than 30 hours a week during transfer receipt, while the associated benefit reduction disincentivizes part-time work. As a result, in 2010, only 1.7\% (less than 9\%) of mothers were part-time employed in the first (last) month of benefit receipt. ${ }^{16}$ Whilst the average total benefit paid to all mothers under the new system was 7,080 EUR in 2007, the scheme paid mothers employed prepartum a benefit of 10,128 EUR in 2008, making the new system considerably more generous than the old (see Table 2). In fact, between 2007 and 2010, take-up of the new leave payment was close to full (about 96\% of all mothers), with many taking advantage of the benefit for the full eligibility period. For instance, the average receipt duration in 2010 was 11.7 months and even those at the top end of the pre birth earnings distribution - who qualified for a monthly transfer of 1,800 EUR - continued taking transfers for an average of 11.2 months. In fact, Figure $2 \mathrm{~A}$, which contrasts the simulated pre and post reform benefit entitlements along the distribution of net yearly labor earnings, 17 shows an almost flat total pre reform benefit

\footnotetext{
${ }^{14}$ The reform additionally introduced two additional months of leave earmarked to the partner or the primary leave recipient ("daddy quota"). Around $20 \%$ of fathers take these two additional months. In order to not discriminate against single mothers, these are eligible to extend their leave by an additional two months.

15 Kluve and Schmitz (forthcoming) show there was a peak in newspaper reports on the new proposed policy as well as a first peak in the Google search index in May 2006, which indicates that the public became increasingly aware of the new potential policy regime from May 2006. However, there was no certainty that the new policy would come into effect before the fall of 2006.

${ }^{16}$ All reported benefit statistics are based on the Elterngeldstatistik for 2007-2010, which covers all benefit claims and is published by the German statistical office.

${ }^{17}$ The simulated pre-reform benefits are the average benefits for various women's income groups
} 
amount across net earnings groups, with post reform benefits continuously increasing in net earnings for most of the earnings distribution. The effective reform effect (i.e., the difference between the two lines) is also continuously increasing in earnings, ranging from -2,400 EUR for yearly incomes under 1,800 EUR to an average benefits increase of 17,100 EUR for women with net (gross) earnings over 33,000 EUR (60,000 EUR). Figure 2B further reveals that whereas pre reform benefits replaced very little of higher income women's foregone earnings relative to those of lower income women, post reform benefits replace at least $67 \%$ of these earnings for all women. In my empirical analysis, I am able to exploit these differentials across socioeconomic groups to identify the policy change's effects.

\subsection{Mechanisms: The Effect of Reform on Fertility Decisions}

Because a major goal of the reform is to lower the cost of potential childbearing by increasing paid maternity leave benefits, it has had a direct financial incentive effect on fertility decisions through increased availability of post birth family resources. In particular, because maternal labor supply in the first years post birth is traditionally low in Germany, the reform is likely to have crowded out either unpaid or paid leave with less generous benefits for many women. Moreover, unlike cash-in-hand benefits such as universal child subsidies, paid leave benefits are conditional on time out of the labor market, meaning that an increase in paid leave benefits could prompt mothers to optimally adjust their maternal labor supply following childbirth. For example, mothers who wish to spend more time at home with their children (and pre reform were potentially credit constrained to do so) may decrease their labor supply and reduce their labor earnings under the more generous regime. Hence, dependent on the magnitude of the maternal labor supply response, the total increase in cumulative family income via the reform is likely to be lower than the increase in maternity leave benefits. 18

The extant literature already offers empirical evidence that the reform encourages leave taking during the period of benefit receipt while reducing maternal employment in the first year after childbirth, particularly for groups who benefit strongly (e.g. Bergemann and Riphahn (2011), Kluve and Tamm (2013), Kluve and Schmitz(forthcoming)). Some such studies even provide tentative evidence for small employment increases in the second year after childbirth. Investigating the effects beyond the first two years post birth, the study by Kluve and Schmitz (forthcoming) finds that the reform in fact

calculated on the basis of the spouse's net income. More details on the simulation of pre-reform benefits are given in Section 4.3 and in Appendix A.

${ }^{18}$ Furthermore, the reform also provided two additional "daddy months" to the family, which may have also changed father's labor supply. Father's take up of leave of around $18 \%$ in 2007 is however modest, which suggests that father's responses to the reform are unlikely to be an important mechanism through which the reform affected fertility. 
encouraged maternal labor supply in the medium term (2 to 5 years after childbirth), probably (at least partly) offsetting the negative short run effects. The overall effect on cumulative maternal labor supply and earnings after childbirth is thus likely to be small 19 At the same time, because the reform provides universal leave benefits with a high income replacement, I expect families' cumulative income to increase in response to the reform.

\section{Empirical approach}

As previously explained, I estimate the causal impact of the paid leave reform on fertility decisions by exploiting the resulting differential changes in benefits across socioeconomic groups. Below, I will first describe the baseline differences-in-differences (DID) empirical strategy estimating the reduced-form effect of the policy. Under the assumption that the reform in paid parental leave affected fertility only through increasing financial incentives, I can then use the reform to estimate the changes in financial incentives on fertility in a second step.

\subsection{Baseline estimation}

Perhaps the most straightforward way to evaluate the reform effects on fertility is to use a simple two-group DID strategy to compare the changes in average fertility between cohorts of high earning versus low earning women (see Figure 3). Figure 3A thus compares the 2004-2012 raw birth probabilities of women with above median earnings of 14.800 (10.098) EUR gross (net) earnings with a control group of women below the median. Whereas before the 2007 reform, the graphs move almost in parallel, after it, the probability of giving birth increases sharply for women above the median but stays roughly constant for women below it. Likewise, as shown in Figure 3B, between 2006 and 2007 maternity leave benefits increase over 6,000 EUR for women above the median but remain almost unchanged for those below. These graphics alone offer initial support for a stronger reform effect on the fertility of higher earning women than on that of lower earning women. I formally test this assumption across the pre (2004-2006) and post reform (2008-2012) periods using a linear probability model that assesses the relative

\footnotetext{
${ }^{19}\left[\begin{array}{l}\text { Kluve and Schmitz } \\ (\text { forthcoming) }\end{array}\right.$ earnings, since the Microcensus they use does not contain precise earnings measures. Using the full population pension registry data and applying a similar RDD-DID estimation strategy comparing women who give birth January 2007 and December 2006 (with January 2006 and December 2005 mothers as the comparison group), I estimate the average reform effect on total cumulative labor earnings in the two years following childbirth to be small and statistical insignificant. The structure of my data does not allow me to look at earnings effect beyond the two years postpartum.
} 
increase in the birth probability for women with above median earnings (treatment group) relative to those with below median earnings (control group):

$$
P\left(\text { Child }_{i t}=\alpha_{0}+\alpha_{1} \text { Treat }_{i t}+\alpha_{2} \text { Treat }_{i t} * R_{t}+X_{i t}^{\prime} \alpha_{3}+\gamma_{t}+u_{i t},\right.
$$

where $P(\text { Child })_{i t}$ is the probability of having a child for woman $i$ in calendar year $t$, Treat $_{i t}$ is a dummy variable equal to 1 if woman $i$ earned below the median in $\mathrm{t}-1, R_{t}$ is a post reform dummy, and Treat $_{i t} * R_{t}$ is the interaction between the two variables. $X_{i t}^{\prime}$, a vector of observed women's characteristics, such as the woman's age dummies, education group, indicator for being in vocational training, German nationality, and region (Länder) dummies, as well as indicators for whether the woman had a child in t-2 or t-1; while $\gamma_{t}$ denotes year dummies. To ensure flexibility of the age effects in covariate vector $X_{i t}^{\prime}$, the model includes dummies for both the age and differential age of tertiary educated women. The coefficient of interest, $\alpha_{2}$, captures the average causal impact of the maternity leave benefit reform on fertility in a given year within the five year post reform period for higher earning women versus lower earning women.

As an alternative, because average earnings differ across education groups, I exploit the variation in reform impact across three different levels of mother's education: (i) no more than secondary schooling (low skilled), (ii) completed vocational training (medium skilled), and (iii) tertiary education (high skilled). Figure 4A plots the unconditional birth probabilities across these three groups for 2001-2011 derived from German Microcensus data on economically active women, which allow the plotting of longer run pre trends than the main data set (see Section 4.3). As in Figure 3A, across-group birth probabilities move almost in parallel before 2007, while post reform birth rates increase for higher educated women and to a smaller extent for medium educated women (who tend to benefit more from the reform than low educated women). Figure 4B, in contrast, shows that between 2006 and 2007, economically active high skilled women enjoyed the largest increase in available maternity leave benefits, 7,136 EUR compared with around 3,527 EUR for medium skilled and only $255 \mathrm{EUR}$ for low skilled women. To exploit these differences, I estimate the following linear probability model:

$$
P\left(\text { Child }_{i t}=\beta_{0}+\beta_{1} \text { Deducmed }_{i t} * R_{t}+\beta_{2} \text { Deduchigh }_{i t} * R_{t}+X_{i t}^{\prime} \beta_{3}+\gamma_{t}+u_{i t},\right.
$$

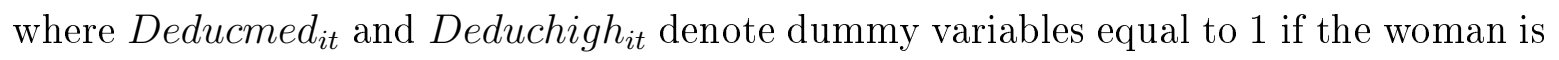
medium or highly educated, respectively. The coefficients of interest, $\beta_{1}$ and $\beta_{2}$ capture the average effect of the reform on fertility for medium and high skilled women relative to low educated women. The identifying assumption of the DID approach is that even if the reform had never happened, the pre and post reform changes in fertility would be 
the same across both the treatment and control groups. Likewise, the graphic evidence for both the earnings and education groups indeed suggests common pre trends but no occurrence of a strong, permanent change in fertility behavior across treatment and control groups until after reform implementation. I assess the validity of this common time trend by running placebo-reforms on the pre reform period data, pretending that the reform occured in the pre reform period. I then test my results' robustness to omitting my set of controls $X$. Deriving similar coefficients from estimates with and without controls would indicate that the sample composition does not corroborate the estimated reform effects, which would point to reform exogeneity with respect to the observed (and potentially unobserved) characteristics of the women.

The DID parameters $\alpha_{2}$ of equation 1 and $\beta_{1}$ and $\beta_{2}$ of equation 2 are intentionto-treat effects (ITT), measuring the reform's reduced form impact on higher earning and higher educated women. A major advantage of these ITT effects is that they capture the full reform impact on fertility decisions through increases in paid maternity leave payments as well as potential endogenous adjustments in labor supply, which can both affect available post birth household income. Moreover, because different earnings and education groups enjoy differential increases in postpartum financial incentives, these reduced form fertility effects can be scaled using variation in the intensity of the maternity leave benefit changes.

\subsection{Effects of changes in maternity leave benefits on fertility}

Although the simplest method for measuring fertility's response to paid leave changes is to divide the DID estimate by the reform-induced benefit differential, using a simple Wald estimator to compare the differential treatment of relatively broad groups does not fully leverage the variation in expected benefit intensity. I therefore estimate a regression model that quantifies the effects of benefit changes and allows me to calculate benefit elasticities, thereby accounting for simulated real expected maternity leave benefits in calendar year $t, B_{i t}$, and for a flexible function of real lagged net earnings, $\Phi\left(E_{i t-1}\right)$ :

$$
P(\text { Child })_{i t}=\delta_{0}+\delta_{1} B_{i t}+X_{i t}^{\prime} \delta_{2}+\Phi\left(E_{i t-1}\right)+\gamma_{t}+u_{i t},
$$

where $P(C h i l d)_{i t}$ is the birth probability for woman $i$ in calendar year $t$. Because of the policy reform, the expected maternity leave benefits $B_{i t}$ vary considerably over time for women with the same real earnings, making post reform benefits $B_{i t}$ a deterministic function of pre birth net earnings in the preceding year, $B_{i t}\left(E_{i t-1}\right)$. Prior to 2007, in contrast, $B_{i t}$ are means tested fixed rate transfers that do not vary in any systematic way with women's pre birth earnings. Hence, I simulate expected benefits in the pre 
reform period using 2006 Micocensus data (as detailed in Section 4.3), but calculate the post reform benefits as a function of net labor earnings in $t-1$, the preceding calendar year.

In order to identify the effect of reform-induced benefit changes on fertility, I must account for a flexible function of lagged net earnings in order to ensure that the variation in $B_{i t}$ comes from the reform-induced variation in benefits over time and not the variation in net earnings levels. ${ }^{20}$ Were I to restrict my analysis to the post reform period, all the cross-sectional variation in benefits would be captured by the flexible earnings controls, preventing me from separately identifying treatment effect $\delta_{1}$. To do the latter, I would need to observe the fertility decisions of observationally equivalent women both pre and post reform. If the time invariant $\Phi\left(E_{i t-1}\right)$ is fully flexible, however, only the reform-induced cross-cohort variation in $B_{i t}$ identifies the treatment effect $\delta_{1}$; that is, the incentive effect of an increase in the total maternity benefit entitlement based on earnings in the previous calendar year $t-1$ on a woman's probability of giving birth in calendar year $t$.

Although no woman need take the maximum maternity benefit entitlement (e.g., some may want to return to work before the 12 th postpartum month), most mothers do in fact take advantage of the maximum paid leave (see Section 2.1), under which condition the benefit estimator measures the impact of a change in financial incentives on the fertility decision. This causal interpretation of the parameter hinges on an additional assumption not needed for the identification of the intention-to-treat effects. That is, the paid maternity leave reform affects the costs of childbearing and in turn impacts fertility decisions only through increased potential leave transfers after birth. ${ }^{21}$ Because receiving maternity leave benefits is conditional on not working, some women might change their labor supply because of the higher leave benefits. If the reform's impact on maternal labor supply and maternal (or family) earnings is negligible, the higher leave benefits will fully translate into an increase in available family income.22

A similar empirical approach is adopted by Dahl and Lochner (2012), who exploit large changes in the earned income tax credit to estimate the impact of family income on child achievement, and by Gruber and Saez (2002), who use tax reform to estimate the elasticity of taxable income. ${ }^{23}$

\footnotetext{
${ }^{20}$ I use a fifth-order polynomial in lagged net earnings in my baseline specification.

${ }^{21}$ Using language from the Instrumental Variable literature, the exclusion restriction has to be met. The reduced form changes in fertility across earnings or education group are solely caused by changes in the potential paid leave benefits, the first stage.

${ }^{22}$ Note that even if the increase in transfers is not equivalent to an increase in available income after the childbirth, I will still identify the impact of increasing conditonal leave benefits on fertility, which captures the optimal adjustment of labor supply. This is still a policy-relevant parameter, but is harder to interpret.

23 Nielsen et al. (2010) and Rothstein and Rouse (2011) use a similar approach to study the effect of
} 
The central identifying assumption of this approach, which is equivalent to the DID assumptions above, is that the relation between shocks affecting fertility decisions and women's net labor earnings remains stable over time. This assumption would be violated if, in the absence of the yreform, differential trends in the fertility decisions across different earnings groups or changes in the composition of earnings groups over time existed that would change the relation between $u_{i t}$ (or benefits $B_{i t}$ ) and lagged labor earnings $E_{i t-1}{ }^{24}$ In this approach, the polynomial $\Phi\left(E_{i t-1}\right)$ can be thought of as a (time-invariant) control function, which in my case must be flexible enough to capture the true relation between women's earnings and fertility. Although I test the robustness of my approach in Section 5.3 and also run a placebo check for the pre reform period, the concern may remain that the reform has motivated women already planning to have a child to increase their labor supply in order to raise their benefit entitlement ${ }^{25}$ If so, an endogenous adjustment in earnings in response to the reform would change the relation between earnings and fertility over time, thereby invalidating my identifying assumption, and assumedly rendering women with the same labor earnings incomparable over time. Whereas the ideal solution to this problem would be to use each woman's pre reform earnings, the data set does not provide such information (see 4.2). Instead, in the appendix, I report several checks that address the concern of endogenous adjustment in the labor supply of pregnant women or women of childbearing age as a response to the reform.

To account for the fact that the preceding year's earnings - and hence, potential benefits as a function of earnings - are potentially endogenous, I also test for robustness when a grouping IV estimator is used to instrument the expected benefits, the most obvious candidate for which is education-year interactions (cf. Blundell et al. (1998)). Using education as my grouping-instrument, I therefore exploit changes in fertility across education groups who were differentially affected by the benefit reform. The DID estimator in equation 2 can be seen as the "Reduced-form" of this IV estimator ${ }^{26}$ The exogeneity restriction here requires that, conditional on controls, education must not affect fertility trends over time in the absence of the reform (the common time trend assumption discussed in 3.1. It also implies that the composition of the education groups (with respect to unobserved differences in fertility) remains stable before

student aid reforms on student outcomes. My estimation strategy is also related to grouping estimators applied to estimate the labor supply effect of tax reforms (see e.g. Feldstein 1995) and Blundell et al. (1998)).

${ }^{24}$ Equivalently, I need to assume that the composition of the treated groups in the standard DID approach in equation 1 and 2 does not change as a response to the reform.

${ }^{25}$ The problem of potential anticipation of treatment effects, which would change the composition of treatment and control groups over time, has been first identified by Abbring and Van Den Berg (2003) for evaluation studies when decision processes are dynamic.

${ }^{26}$ Moffitt and Wilhelm (2000) and Blundell et al. (1998) discuss the equivalence between DID estimators and (grouping)-IV estimators. 
and after the policy reform. This assumption would be violated if economic shocks or preference shifts that affected education group differently resulted in differential fertility time trends across education groups. Although the 2007-2009 financial crisis would seem an obvious possibility, in my case, its threat is limited because, thanks to a strong upward economic trend beginning in the mid 2000s, the German economy, unlike those of most other European countries, suffered no lasting impact ${ }^{27}$ The reform is also unlikely to have affected the educational attainment of the cohorts studied because these latter had made most educational decisions before the policy switch and experienced no major educational reforms over the time span studied. Hence, endogenous switching of education groups in order to increase benefits is unlikely to pose a threat to identification. I estimate the empirical models on a restricted sample of women over 20 and under $452^{28}$ and exclude 2007 data from the main empirical analysis because, the reform legislation having been passed in Fall 2006, only individuals giving birth from Summer 2007 onward could have adjusted their fertility behavior in response.

\section{Data}

My analysis draws on three different data sources: German vital statistics, the German Microcensus, and administrative records for insured persons from the German Pension

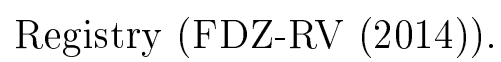

\subsection{Vital Statistics}

To study the time trends in fertility and test for a discontinuous jump in the number of births 9 months after announcement of the reform, I use micro data from the German Statistical Office's (GSO) vital statistics on all births in a given month for 2000-2011. I supplement these data with aggregate GSO information on the female population by age to construct monthly birth rates.

\subsection{Pension Registry Data}

The main analysis uses administrative data on insured persons compiled by the German Federal Pension Insurance's (FDZ-RV) Research Data Center. This highly precise pension registry covers all those who made any contribution in the reporting year to the statutory pension insurance, which is mandatory for all employed persons in the private

\footnotetext{
${ }^{27}$ Unemployment rates have been falling between 2006 and 2011 across all education groups. For a more detailed account on the evolution of employment rates see Weber and Weber (2013).

${ }^{28}$ Childbearing for women age 20 and under is relatively scarce; around $3 \%$ of all births in 2007 were to mothers below the age of 21 . Childbearing above 44 is extremely rare as $99.8 \%$ of births are to women age 44 or younger.
} 
and public sectors, including marginal employment. Excluded from the data set are the economically inactive, civil servants (including teachers), and most self-employed, none of whom are covered by statutory pension insurance. ${ }^{29}$ Because childbearing entails a pension contribution period, these social security data provide a fertility record for any woman who has ever been registered with the pension insurance, which accounts for $91 \%$ of all births recorded in the vital statistics in 2007.

For my main results, I draw on the scientific use file of the insured persons database for 2004-2012 (FDZ-RV (2014)), which represents 1\% of the full population of insured persons and contains annual information on over 80,000 women aged 21-44. These crosssectional data include information on the fertility and employment on 31st December in the reporting and two preceding years, as well as a woman's educational level and yearly gross labor earnings for the reporting and previous year. To avoid changes in the sample composition stemming from benefit reforms in the earlier 2000s, I restrict my sample to all women aged 21-44 who had positive labor earnings in the year preceding the survey, thereby excluding women who lived solely on unemployment benefits during that time 30

I calculate the expected post reform maternity benefits using a detailed maternity benefit calculator (http://www.familien-wegweiser.de/Elterngeldrechner), which generates the expected maximum benefits as the sum of monthly benefits over the total 12-month entitlement period as well as a woman's net earnings based on information on a woman's gross earning reported in the pension registry data.

\subsection{Microcensus}

To simulate the pre reform benefits, assess pre reform trends, and estimate the DID results by education, I employ a $70 \%$ subsample (the Scientific Use File (SUF)) of 2003-2012 data from the German Microcensus, an annual cross-sectional survey of a random $1 \%$ sample of the German population ${ }^{31}$ This survey gathers household demographics on around 70,000 women aged 21 to 44 each year, including number and ages of children in the household, marital status, education and vocational training, labor market participation, and receipt of various benefits. Nevertheless, because the survey is administered continuously over the year, its data on births in the current year do not

\footnotetext{
${ }^{29}$ Kohls (2010) reports that data on insured persons for ages 20-59 covers $84.5 \%$ of German women and $86.1 \%$ of German men and $67.2 \%$ of non-German women and $75 \%$ of non-German men respectively in terms of the 2006 population estimation.

${ }^{30}$ Around $8 \%$ of economically active women were solely receiving unemployment benefits. As outlined above, the Pension Registry data contains information on economically active (employed women as well as unemployed women), but only contains information on inactive women if they are giving birth in that year. Hence I can not not determine the probability to give birth for inactive women.

${ }^{31}$ The data used in this paper was analyzed using the remote processing tool JoSuA. JoSuA was developed by the IDSC of IZA. See Askitas (2008) for details.
} 
allow determination of birth probability in the survey year. Rather, I retrospectively derive this probability for the preceding year from the children's actual birth years 32 although 2012 data being the most recently available, I can do so only up until 2011.

Whereas the representativeness of this data set (whole population, including the economically inactive, civil servants, and the self-employed) is one of its major advantages, ${ }^{33}$ it unfortunately means that the income measures for the survey year are relatively broad. Nonetheless, for every household member, it does provide a measure of net income, reported in intervals, for the month preceding the survey date. Because expected pre reform maternity benefits in essence depend solely on partner's income, I can calculate them for each woman by applying the pre reform benefit eligibility rules to her spouse's net income and aggregating this information by income or education-age group (from the 2006 Microcensus data) for all women aged 21-45. I then merge the averages by a woman's observable characteristics with the pension registry data, implicitly assuming that expectations of benefit level are formed on the basis of partner's current income. ${ }^{34}$ For my baseline results (Section 5.3), I define the expected benefits as the sum of monthly payments over the maximum 24-month entitlement period with the assumption that mothers maximize their total benefit entitlement (see Appendix A for simulation details for both pre and post reform benefits).

According to the descriptive statistics for the estimation sample, which are based on information from both data sets (Table 3, Panel A), on average, the maternity benefits for which women are eligible are less than 5,000 EUR pre reform but increase to 8,280 EUR post reform. Around $91 \%$ of the women in the sample are German nationals, with an average age of 33.37 years - 30.67 for new mothers - and a probability of giving birth in a given year of $4.1 \%$. The majority has vocational training (62\%), around $15 \%$ are tertiary educated, and $24 \%$ have no postsecondary degree. 35 Median earnings in the preceding year are 10,114 EUR net (14,874 EUR gross), with a women in the 90th percentile of the earnings distribution taking home around 21,540 EUR net $(36,091$ EUR gross). According to Table 4, Panel B, $27 \%$ of the women are mothers to one child and $25 \%$ have two children; however, close to $40 \%$ of women aged 21-44 are childless. Given the large share of potential first-time mothers, if my analysis is to truly capture

\footnotetext{
${ }^{32}$ As Brewer et al. (2010) point out, birth probabilities estimated by this approach are potentially subject to measurement error due to infant mortality and household reconstitution, but low rates of mortality and the fact that the overwhelming majority of children stay with their natural mother in the event of family breakup reduce the effect of these factors in practice.

${ }^{33}$ According to own calculations based on the Microcensus 2010 , around $8 \%$ of all (11\% of working) women between age 20-44 were self employed or civil servants.

${ }^{34} \mathrm{I}$ also have to implicitly assume that assortative matching of partners is the same over time.

${ }^{35}$ Educational information is based on the Microcensus sample, which is representative of all women. As mentioned earlier, the pension registry data does not include self-employed and civil servants. As a result, the share of highly skilled in the pension registry data sample is lower (8\%). Around $70 \%$ $(22 \%)$ of women in the pension registry data are medium skilled (low skilled).
} 
the full effect of the reform, it must consider all births, including first births, rather than focusing on higher order births only.

\section{Results}

To estimate the reform's impact on fertility decisions, I first derive DID estimates of its reduced form effects and then conduct a benefit analysis that exploits the variation in financial incentives across earning groups. In addition to the results using education groups as an instrument, I also report an estimate of the benefit elasticity. Before turning to my main regression analysis, however, I perform a time series analysis such as that reported by González (2013) and present evidence for the immediate adjustment of fertility in response to the reform announcement.

\subsection{Descriptive evidence from time series}

To derive the time series of monthly birth rates, I first plot seasonality adjusted (residual) monthly number of births per 1000 women over the 2004-2011 period (Figure 2). I additionally plot a lowess smoother separately for the months before and after August 2007 (0-cutoff month in Figure 2), which is 9 months after the final passing of the policy change in November 2006, when it was certain to come into effect. The dotted line (-5) denotes March 2007, 9 months after announcement of the policy change (May/June 2006). Up until the cutoff date, the monthly birth rate appears to be relatively stable but jumps discontinuously in the cutoff month of August 2007 and continues to increase thereafter. I also perform a regression test for a discontinuity around August 2007 using a third-order polynomial in the running variable (birth months over time) to capture smooth fertility trends and calendar month dummies to measure birth seasonality ${ }^{36}$ This test yields an estimate of about 0.17 (standard error 0.061 ), equivalent to around $3.5 \%$ of the pre August 2007 average monthly birth rate of 4.87 births per 1,000 women, implying that these latter increased a significant 3.5\% in August 2007 over the previous month. The result hence suggests that births per 1000 women increased significantly in August 2007 compared to the previous month by about 3.5\%. Extrapolating to the yearly level using around 673,000 live births for 2006 (Statistisches Bundesamt (2016)), I find that policy implementation results in close to 2.350 additional children born each year in the very short run. Given the three to six months needed for conception even in a fertile couple (González (2013)), however, the discontinuity is capturing only the

\footnotetext{
${ }^{36}$ I estimate the specification $B_{m}=\alpha+\beta *$ post $+\gamma_{1} m+\gamma_{2} m^{2}+\gamma_{3} m^{3}+\sum_{i=2}^{12} \delta_{i}$ Dmonth $_{m}+\varepsilon_{m}$, where $B_{m}$ is the respective fertiliy rate in months $m$, post takes value 1 starting in August 2007 and $\mathrm{m}$ is a running variable for months in the sample period (i.e. value of 1 for January 2004). Dmonth $h_{m}$ denotes calendar month dummies. The regressions results are available upon request.
} 
very immediate response in successful conceptions following passage of the law and is thus likely to understate the true immediate fertility response to the policy ${ }^{37}$

\subsection{Differences-in-differences results for earnings and education groups}

In calculating the DID estimates for the up to 5 year post reform impact for the treatment group of women above median earnings (equation (1)), I address potential selection bias by estimating the effects both with and without the set of individual controls, expressing the dependent variable as births in 1,000 women for ease of interpretation. As Table 4, column (1) shows, over the 5-year post reform period, the reform in paid maternity leave increases the birth probability in a given year by 7.2 births per 1,000 women. Evaluated against the corresponding pre reform birth rate of 41 births per 1,000 women, this estimate implies that the fertility of women with above median earnings increases by $18 \%$ in response to the reform. To place this estimate in perspective, Lalive and Zweimüller (2009) find that extending leave for a current (future) child increases short run fertility (i.e., within three years) by $15 \%$ (21\%) with the larger effect for a future child most similar to the reform effect identified here. Milligan (2005) identifies similar fertility effects for child subsidies, $10.7 \%$ for the first child and $25 \%$ for families with two or more children, who are the most affected by child subsidy changes. The fact that my baseline estimate is robust both to excluding all individual level control variables (column (2)) and to including a second-order polynomial in earnings as a finer measure of previous year earnings (column (3)) suggests that the estimate of the reform impact is not sensitive to the composition of either the treated or control group.

In columns (4) and (5), I apply an alternative definition of treatment and comparison groups, whose differential birth rate evolution is outlined in Figure A1. First, in column (4), I compare the evolution of birth probabilities for women in the top decile of the earnings distribution (above 36,000 EUR gross earnings) with that of women in the bottom decile (under 3,250 EUR). This estimate indicates a reform-induced increase in the fertility of top earning women in a given year of 1.2 percentage points $(27 \%)$. Not surprisingly, given the substantial post reform increase in maternity leave (around 14,000 EUR) for women in the top decile relative to the bottom decile, the reform effect is larger than for the baseline treatment definition in (1). Hence, in column (5),

\footnotetext{
${ }^{37}$ Terminations of pregnancies in turn can immediately adjust to the policy. I find some suggestive evidence using quarterly numbers of abortions that the policy appears to have discouraged abortions for married women, with no apparent trend change for single women. I also find a strong increase in aggregate data on In Vitro Fertilisation (IVF) between 2006 and the post-reform period which likely reflect the increase in the willingness to conceive, in particular by older women. The results are available on request.
} 
I restrict the sample to women within the interquartile range of earnings to create treatment and control groups of women between the 50th and 75th percentile and 25 th and 50th percentiles, respectively. The estimated reform effect confirms that women who experience a higher increase in paid leave also increase their fertility more strongly. The last column of Table 4 then reports the estimate of a placebo test in which the reform has already occurred in 2006 and the data are restricted to the pre reform years of 2004-2006. Consistent with the graphic evidence of similar pre reform trends for both treatment and comparison groups, which only diverge sharply post reform (Figure 3), the estimated effect for the placebo reform is insignificant and the point estimate of much smaller magnitude than the true reform effect in column (1).

I next use the 2004-2011 Microcensus data to calculate alternative DID estimates of the reform for medium and high skilled women (the treatment groups) relative to low skilled women (the comparison group) from equation (2) (for more details on the educational coding, see Appendix A). For this analysis, I estimate the reform effects for the full population of women, including the economically inactive, self-employed, and civil servants, to enable estimation of the reform effects for the full population of women, again using the data on the number and age of children in the family. According to these results (column (1)), the birth probability for high skilled women increases by 8.47 births per 1,000 women in a given year post reform, which when evaluated against the pre reform mean, constitutes a $15 \%$ increase in fertility. Omitting the individual level controls (column (2)) and adding measures of family composition (column (3)) yields very similar results.

On the other hand, estimating the reform effects for all women including the inactive yields only a small, statistically insignificant point estimate for medium skilled women, which is hardly surprising given that (i) the reform gives inactive women no increase in paid maternity leave on average and (ii) these DID estimates are reduced form effects of the policy. As a result, the corresponding first stage coefficient (i.e., the average change in benefits for education groups) is simply smaller when the inactive are included. Conversely, because the sample of active women benefits more strongly from the reform, restricting the data to economically active women (column (4)) while excluding civil servants and the self-employed to match the pension registry sample (column (5)) results in the expected increase in the estimated reform effect for both education groups. In particular, when only active women are included, the reform augments the fertility of highly educated active women by close to 22 births per 1000 women (see Figure 4).

The longer timespan covered by the Microcensus data also allows estimation of placebo reforms over a lengthier period. I thus redefine my pre and post reform periods as 2001-2003 and 2004-2006, respectively, and estimate placebo reform effects for the 
whole sample (columns (6)) and the sample of economically active women (column (7)). In line with the pre reform trends depicted in Figure 4, the placebo estimates are insignificant, suggesting that education groups experience no differential time trends prior to the reform. As a final step, I replicate the education group analysis using the sample of active women in the 2004-2012 pension registry data (Table A1, column (1)) and show that the results are of similar magnitude for the highly skilled, whose fertility the reform increases by 18\%, but larger for the medium skilled (a 13\% increase).

\subsection{Baseline results for benefit estimation}

Before reporting my estimation results of equation (3), I construct a discretized version of the previously outlined continuous benefit estimator by discretizing the net earnings distribution into 10 intervals. Each of the first nine represents 3,000 EUR while the last contains all real net earnings beyond 27,000 EUR (gross earnings of ca. 47,000 EUR), which lies above the 95th percentile of the earnings distribution $(25,085$ EUR net). I then estimate a linear probability model that controls for these earnings interval dummies and their interaction with a post reform dummy, as well as controls from my baseline specification. 38 By plotting the coefficient estimates (and 95\% confidence intervals) for the earnings interactions with the post reform dummies, I reveal a very different fertility evolution along the earnings distribution (Figure 5A). In this evolvement, no women below the earnings interval of 9,000-12,000 EUR (midpoint 10,500) are any more likely to have a child post reform, but those with earnings below 3,000 EUR, which corresponds to the bottom $10 \%$, actually experience a statistically significant decline in fertility. Women who are at or above the 50 th percentile (median = 10,100 EUR, around 14,800 EUR gross) of the net earnings distribution, however, have a significantly increased probability - around 3-8 children in 1,000 women or $0.3-0.8$ percentage points - of having a child in any of the 5 years post reform. Even women in the top earnings interval who are above the 95 th percentile are statistically significantly more likely to give birth post reform (6.4 births in 1,000 children). In fact, the relatively stable post reform surge in childbearing for above-median earners (Figure 5A), with benefits steadily increasing despite increasing income (Figure 5B), implies that the effect of paid leave benefits on fertility may be stronger for the middle-upper part of the income distribution than for the top end.

Next, defining benefits as the sum of benefits in 1,000 EUR (in 2010 prices) that a woman could expect for giving birth, I estimate the baseline for equation (3), which

\footnotetext{
${ }^{38} \mathrm{I}$ estimate the following specification, $P(\text { Child })_{i t}=\eta_{0}+\sum_{e=1}^{10} \theta_{e}\left(R_{t} * d_{e i t}\right)+X_{i t}^{\prime} \eta_{1}+\sum_{e=1}^{10} \gamma_{e} d_{e i t}+$ $u_{i t}$, where $d_{e i t}$ is a dummy variable, $d_{e i t}=1\left\{e_{j} \leq E_{i}<e_{j+1}\right\}$, indicating that earnings of woman i lie within the ten earnings intervals $\left(E_{i} \in\{1,2 \ldots, 10\}\right)$ of length $3000 \mathrm{EUR}, R_{t}$ is a post (2007)-reform indicator.
} 
requires the inclusion of a flexible function of lagged net income. Before making the more conservative choice of a fifth-order polynomial, I explore differently-ordered polynomials but find very similar estimates from order two onward. The baseline result in column (1) implies that an increase in the total expected benefits of 1,000 EUR increases the probability that a woman will give birth in each of the five post reform years by 0.783 births per 1,000 women. In terms of the average pre reform birth probability, this figure implies a rise in fertility in a given year of $2.1 \%$ per 1,000 EUR in total benefits, slightly smaller than reported in the extant literature. Milligan (2005), for example, finds that a 1,000 CAD (around 690 EUR) increase in the total sum of 5-year benefits would increase fertility on average by $2.6 \%$. On the other hand, the estimates by Lalive and Zweimüller (2009), who report an estimated future child effect of $21 \%$ (or $7 \%$ points over three years) and a maximum benefit increase of 4,080 EUR, imply around a $5 \%$ increase in fertility per 1,000 EUR increase in extended maternity leave benefits for the second year of a child's life.39

The fact that my baseline estimate is robust to the omission of individual level control variables (column (2)) suggests that reform implementation is exogenous with respect to observable characteristics. Furthermore, I check whether the fifth-order polynomial in lagged net earnings as my choice of control function in my baseline specification is flexible enough to control for the relation between earnings and fertility. In (column (3)), I include only a second-order polynomial in net earnings, which yields a similar estimated reform effect. In column (4), I address the concern that the effect of net earnings on fertility decisions might differ by women's characteristics by employing a more general form of the control function that is allowed to vary by woman's education level. The estimated benefit effect, however, does not change. In column (5), I then report estimates for a placebo reform, assuming earnings-dependent benefits had already been introduced in 2006, and use the pre reform data only to test the differential changes in fertility over the 2004-2006 period. The estimated effect for this placebo reform is insignificant and the point estimate very close to zero.

Up this point in the analysis, I have defined pre reform benefits as the simulated sum of benefits under the 24-month entitlement period option, which has a maximum of 300 EUR monthly (7,200 EUR in total). However, the scheme also allows women to opt for a shorter entitlement period, with a maximum 450 EUR for 12 months (5,400 EUR in total). This option, which is more popular among East German women, is particularly attractive for mothers wanting to return to work after 12 months. I thus redefine the pre reform benefits as the expected sum of benefits under the shorter 12-

\footnotetext{
${ }^{30}$ Lalive and Zweimüller $(2009)$ report on p. 1366 that extending leave for the future child increased fertility by $21 \%$. I combine this number with the maximum amount of additional paid leave for the second year of a child's life (340 EUR a month*12).
} 
month option (column (6)). Furthermore, I have simulated and matched the pre reform benefits by women's income. Alternatively to my baseline specification, I simulate and match the 24-month option for women's education-age groups of 5 years (column (7)). Both redefinitions of pre reform benefits have little effect on the estimated coefficient, suggesting that the results are robust to alternative benefit definitions.

I next show the robustness of the baseline results of the benefit estimator when a grouping IV estimator is used to instrument the expected benefits before, followed by evidence on the robustness of the baseline estimate to the functional form chosen.

In the two subsections below, I demonstrate the robustness of the baseline estimate(s) when (i) the expected benefits are instrumented with a grouping IV estimator and (ii) different functional forms are assumed.

IV results using variation across education groups: The estimates in Table 6 would be biased if women adjusted their earnings in response to the reform; however, I find no evidence that mothers increase their pre birth earnings or working hours (Table A2, Panel A) or that they are more likely to enter the labor market (Panel B) as a reform response. Nor is there any evidence of employment adjustments by women of childbearing age (see Table A3). Nevertheless, because education groups explain much of the variation in benefits over time, identifying them as a strong instrumental variable, in column (8), I check the robustness of my estimates to instrumenting leave benefits with education-year interactions, exploiting the variation in education-year specific mean benefits for identification. The partial R2 of the education-year interactions in the first stage is 0.111 with a first stage F-statistic of 4,859. The IV point estimate of 1.096 is slightly larger but not statistically significantly different from the baseline estimate in column (1). This estimate implies that a 1,000 EUR increase in expected maternity benefits raises a woman's birth probability in one of the five post reform years by 1.096 births in 1,000 women, an increase of $2.9 \%$ relative to the pre reform mean.

Robustness of benefit estimates to functional form: Table 7 presents several specifications exploring the robustness of the baseline estimates to the functional form chosen. First, specification A relates maternity benefits directly to the opportunity costs of birth, proxied by the net earnings in t-1. Here, I define benefits in terms of their replacement ratio for net earnings, which ranges between $12 \%$ for high earners and $160 \%$ for very low earners before 2007 but lies above $67 \%$ for almost all women after the reform 40 The mean reform-induced increase in the replacement ratio is about 29 percentage points, with a standard deviation of 9.55 (estimated using the 2006 pension data). More specifically, I estimate that a 10 percentage point increase in the replace-

\footnotetext{
${ }^{40}$ Women with net earnings above about 33,000 EUR (around 59,500 EUR gross) receive the maximum monthly benefit irrespective of their income, so their replacement rates lies below $67 \%$, but this only affects a marginal fraction of less than $2 \%$ of my sample.
} 
ment ratio increases the probability of having a child by 1.37 births in 1,000 women, a $3.6 \%$ increase over the average pre reform probability.

Because the effects of additional benefits may be stronger for lower income women and thus decreasing with benefit level, specification B uses the log of total expected benefits (together with a polynomial in log real net earnings) as an alternative explanatory variable, thereby enabling the calculation of the benefit elasticity. Here, a $10 \%$ increase in benefits raises birth probability by 0.71 births per 1,000 women, a $1.9 \%$ increase relative to the pre reform mean. This increase implies an average benefit elasticity of 0.19, ${ }^{41}$ which conforms to the existing literature. For example, Cohen et al. (2013) and Milligan (2005) find benefit elasticities of child subsidies of 0.19 and 0.107 , respectively, which are in the same range of estimates as those in time-series studies (see Milligan (2005), p. 551).

\section{Heterogeneity by age and birth order}

As previously emphasized, because women may change the timing rather than the total number of children borne during their fertile years, my estimates reflect the medium run impact of financial incentives on current rather than permanent fertility. Nonetheless, Figures 3 and 4 show a clear upward trend in the fertility behavior of higher earning and highly educated women 5 years post reform, suggesting that the latter has had a lasting positive impact on the fertility behavior of affected groups. In addition, although public perceptions of the coalition-generated reform as a permanent change affecting childbearing costs may have resulted in delayed reactions in younger women, increased financial incentives are likely to have led to permanent increases in the fertility of women closer to the end of their childbearing years (cf. Cohen et al. (2013)). Post-reform, they face lower costs for an additional birth under the new parental leave benefit system, which might induce them to have a(n additional) child. Facing the new benefit system, I expect older women to not postpone an additional birth for too long and adjust their fertility fairly fast. Their remaining time to conceive is very limited with the probability to conceive decreasing over their remaining fertile years. In other words, the lower costs faced by these women under the new maternity leave benefit system may have induced them to add to their families. Hence, post reform, I expect that older women, with very limited time to conceive and decreasing fertility likelihood, will adjust their fertility relatively quickly rather than postponing an additional birth for any length of time.

As shown by the separate regressions of equation (3) for the five age categories

\footnotetext{
${ }^{41}$ Alternatively I can use the DID estimates above to calculate benefit elasticities by relating the \%-change in fertility to the \%-change in benefits. I calculate the benefit elasticity to be around 0.2 women above median earnings and 0.15 for high-skilled women.
} 
(Table 8, columns (1)-(5)), the reform does indeed appear to have affected fertility across all age groups, even though the estimated reform effects for some falls short of the 10\% significance level. Even women aged 25-29 (column (2)) increase their fertility in response to the higher maternity benefits offered. Nonetheless, my estimations of a fully interacted specification do not allow me to reject the equality of the estimated reform effect across age groups other than for the oldest women, aged 40-44, for whom the effect is statistically significantly different compared to women aged 25-29 and 3539 (columns (2) and (4)). The 40-44 age group (column (5)) is of particular interest because of the large magnitude of the effect in terms of underlying probability: an additional 1,000 EUR of maternity leave benefits increases a women's probability of having a child in that same year by nearly 5\%. The results for this and the 35-39 age group, both nearing the end of their fertility cycle, suggest that the increased financial incentives have had a permanent effect on fertility and will increase the completed fertility of these cohorts.

In addition, although this analysis so far only documents a reform effect on overall birth probability, a number of studies (e.g. Laroque and Salanié (2014) and Brewer et al. (2011)) show that it also tends to affect the decision on first births (extensive margin) differently than that on second or higher order births (intensive margin). The detailed information on number and age of children provided by the Microcensus allows me to test whether the reform does indeed affect the fertility of highly educated women at different parities. Estimating a DID specification which allows for differential effects of the reform by birth order, I find that for highly educated women across all age groups, the reform has strongly impacted the decision to have not only a first but also a second or higher order child (Table A4, Panel A). Of particular interest in terms of completed fertility are the reform effects across parities for women aged 40-44, whose childlessness it seems not to effect (Table A4, Panel B). Rather, the increase in permanent fertility established previously (Table 8, column (5)) is driven by the decision to have a(n additional) second child rather than one child as a response to the reform, with a large gap in completed fertility across education groups at the intensive margin. That is, in $2012,53.4 \%$ of highly educated women aged 45-49 had at most one child, a 15 percentage point higher share than for women without any postsecondary education (BIB (2012)). Based on my findings, this substantial gap in births beyond the first child is likely to narrow as a result of the reform.

\section{Discussion and Conclusion}

In this paper, I assess the ability of Germany's introduction of earnings-related paid maternity leave to increase fertility, especially for higher earning women with high 
opportunity costs of childbearing. In particular, by taking advantage of the large differential changes in maternity leave benefits across education and income groups, I am able to use a DID approach to identify the direct fertility effect of the changes in paid leave for the child yet to be born. My findings in fact suggest that the higher benefits to higher earning women - up to 21,000 EUR as an exogenous source of variation in entitlement - have actually changed the socioeconomic structure of fertility. Not only do my baseline estimates indicate that a 1,000 EUR increase in total leave entitlements raises the average birth probability by $2.1 \%$, but other results for effects along the earnings distribution suggest that the reform has increased the fertility of women with median earnings and above, including the top 5th percentile. The policy also induces highly educated women to give birth to 8.5 additional children per 1,000 women in a given year over the 5 years post reform. Admittedly, this observed fertility response could be transitory rather than permanent; however, the strong reform effects observed for women aged 35-39 and 40-44 suggest that it is likely to have a permanent effect. Especially noteworthy is the fact that under the new system, highly educated women are more likely to have a(n additional) second (rather than first) child at the end of their fertility cycle, signaling a change at the extensive margin.

Taken together, my findings suggest not only that earnings-related maternity leave programs are successful at increasing fertility overall, but that the policy has successfully raised fertility, particularly for women with higher opportunity costs of childbearing who were given very low financial incentives under the previous flat benefit scheme. Such leave therefore appears to be a more effective policy than traditional schemes like child subsidies or cash benefits for incentivizing fertility in women with higher opportunity costs. The findings thus imply that paid maternity leave could help mitigate the general fertility declines associated with women's increasing labor market participation, thereby narrowing the existing baby gap between education and earnings groups. Yet neither the effect of maternity leave on fertility decisions nor the socioeconomic composition of fertility is as yet receiving adequate research attention. Rather, the maternity leave literature focuses largely on the direct effect of extending maternity leave on mothers' labor supply and the outcomes of children already born. Hence, providing causal evidence on how the German policy changes have affected fertility patterns is important for all countries facing low fertility rates, which are a risk to the long-term sustainability of public pension systems.

In addition, the fact that my quasi-experimental approach identifies only reducedform fertility responses under the assumption of a fixed short run investment in human capital up to 5 years post reform raises interesting possibilities for extending the work. Thus future researchers might, for example, analyze the long run effect of the reform on potential human capital investment and labor supply in a dynamic structural framework 
(see Adda et al. (2017)). Within such a long term perspective, women would face lower expected opportunity costs of childbearing because of higher earnings replacement of leave payments, so younger women in particular might respond by increasing their investment in human capital.

The narrowing of the baby gap identified in this paper is economically important because when intergenerational mobility in education or income is limited, ${ }^{42}$ this narrowing is likely to have important distributional implications for future generations. In fact, Werding and Hofmann (2006) and Sinn (2013) predict that a child with above average earnings ( $150 \%$ of the average) born in 2000 will have an almost 220,000 EUR larger fiscal gain from the German social security system than the average newborn child, whose net gain will be close to 80,000 EUR. The changes observed in the socioeconomic structure of fertility have similarly serious implications: in particular, if the introduction of earnings-related maternity leave, by changing the composition of future generations, improves their education and labor market outcomes (and with that their taxable income), then the case for maternity leave programs is likely to be stronger.

\footnotetext{
${ }^{42}$ The intergenerational correlation between parental and child education is high and estimated to be around 0.4-0.5 for the US and most Western European countries (see for instance Hertz et al. (2008) as well as Black and Devereux (2011) who discuss the potential underlying mechanisms for the observed correlation in education).
} 


\section{References}

Aaronson, D., Lange, F. and Mazumder, B. (2014). Fertility Transitions along the Extensive and Intensive Margins. American Economic Review, 104 (11), 3701-3724.

AbBring, J. H. and VAn Den Berg, G. J. (2003). The nonparametric identification of treatment effects in duration models. Econometrica, 71 (5), 1491-1517.

Adda, J., Dustmann, C. and Stevens, K. (2017). The career costs of children. Journal of Political Economy, 125 (2), 293-337.

Askitas, N. (2008). Data documentation and remote computing at the international data service center of iza. IASSIST Quarterly, 32.

BAKer, M. and Milligan, K. (2008). Maternal employment, breastfeeding, and health: Evidence from maternity leave mandates. Journal of Health Economics, 27 (4), 871-887.

- and - (2010). Evidence from maternity leave expansions of the impact of maternal care on early child development. Journal of Human Resources, 45 (1), 1-32.

Baughman, R. and Dickert-Conlin, S. (2003). Did expanding the EITC promote motherhood? American Economic Review, 93 (2), 247-251.

Bergemann, A. and Riphahn, R. (2011). Female labour supply and parental leave benefits - the causal effect of paying higher transfers for a shorter period of time. Applied Economics Letters, 18 (1), 17-20.

BIB (2012). Frauen der Geburtsjahrgänge 1937 bis 1942 und 1963 bis 1967 nach Anzahl der Kinder und Ausbildungsabschluss in Deutschland (Stand: 2012). URL: http://www.bib-demografie.de/DE/ZahlenundFakten/06/Abbildungen/ a_06_25_frauen_geburtsjahrgaenge_1937_1942u1963_1967_anzahl_kinder_ ausbildungsabschluss_d_2012.html?nn=3073508 [Date: 23 Sep 2016].

BjÖRklund, A. (2006). Does family policy affect fertility. Journal of Population Economics, 19 (1), 3-24.

Black, S. E. and Devereux, P. J. (2011). Chapter 16 - recent developments in intergenerational mobility. In David Card and Orley Ashenfelter (ed.), Handbook of Labor Economics, vol. Volume 4, Part B, Elsevier, pp. 1487-1541.

Blundell, R., Duncan, A. and Meghir, C. (1998). Estimating labor supply responses using tax reforms. Econometrica, 66 (4), 827-861. 
BMFSFJ (2008). Elterngeld als Teil nachhaltiger Familienpolitik. URL: https://www.bmfsfj.de/bmfsfj/service/publikationen/ elterngeld-als-teil-nachhaltiger-familienpolitik/73822.

Brewer, M., Ratcliffe, A. and Smith, S. (2011). Does welfare reform affect fertility? evidence from the UK. Journal of Population Economics, 25 (1), 245-266.

BundesRegierung (2006). Rede von Bundeskanzlerin Angela Merkel beim Arbeitgebertag 2006. URL: http://archiv.bundesregierung.de/nn_774/Content/DE/ Archiv16/Rede/2006/11/2006-11-07-rede-bkin-arbeitgebertag.htm] [Date: 01 Nov 2013].

Carneiro, P., Løken, K. V. and Salvanes, K. G. (2014). A flying start? maternity leave benefits and long-run outcomes of children. Journal of Political Economy, 123 (2), 365-412.

Cohen, A., Dehejia, R. and Romanov, D. (2013). Financial incentives and fertility. Review of Economics and Statistics, 95 (1), 1-20.

Cygan-Rehm, K. (2015). Parental leave benefit and differential fertility responses: evidence from a German reform. Journal of Population Economics, 29 (1), 73-103.

DAhl, G. B. and Lochner, L. (2012). The impact of family income on child achievement: Evidence from the earned income tax credit. American Economic Review, 102 (5), 1927-1956.

-, Løken, K. V., Mogstad, M. and Salvanes, K. V. (2016). What Is the Case for Paid Maternity Leave? Review of Economics and Statistics.

Dustmann, C. and SchönBerg, U. (2012). Expansions in maternity leave coverage and children's long-term outcomes. American Economic Journal: Applied Economics, 4 (3), 190-224.

FDZ-RV (2014). Ausführliche Datensatzbeschreibung, Codeplan, Scientific Use File Aktiv Versicherte 2004- 2012, Querschnittdaten-Basisfiles-Archiv. Tech. rep., Forschungsdatenzentrum der Rentenversicherung.

Feldstein, M. (1995). The effect of marginal tax rates on taxable income: A panel study of the 1986 tax reform act. Journal of Political Economy, 103 (3), 551-572.

GonZÁLEZ, L. (2013). The effect of a universal child benefit on conceptions, abortions, and early maternal labor supply. American Economic Journal: Economic Policy, 5 (3), 160-188. 
Gruber, J. and SAEz, E. (2002). The elasticity of taxable income: evidence and implications. Journal of Public Economics, 84 (1), 1-32.

HeCkMan, J. J. and WalkeR, J. R. (1990). The relationship between wages and income and the timing and spacing of births: Evidence from swedish longitudinal data. Econometrica, 58 (6), 1411-41.

Hertz, T., Jayasundera, T., Piraino, P., Selcuk, S., Smith, N. and VeRASHCHAGinA, A. (2008). The inheritance of educational inequality: International comparisons and fifty-year trends. The B.E. Journal of Economic Analysis 85 Policy, $7(2)$.

Hotz, J. V., Klerman, J. A. and Willis, R. J. (1997). Chapter 7 the economics of fertility in developed countries. In Mark R. Rosenzweig and Oded Stark (ed.), Handbook of Population and Family Economics, vol. Volume 1, Part A, Elsevier, pp. $275-347$.

Keane, M. P. and Wolpin, K. I. (2010). The role of labor and marriage markets, preference heterogeneity, and the welfare system in the life cycle decisions of black, hispanic, and white women*. International Economic Review, 51 (3), 851-892.

Kluve, J. and Schmitz, S. (forthcoming). Back to work: Parental benefits and mothers' labor market outcomes in the medium run. Industrial and Labor Relations Review, (forthcoming).

— and TAmm, M. (2013). Parental leave regulations, mothers' labor force attachment and fathers' childcare involvement: evidence from a natural experiment. Journal of Population Economics, 26 (3), 983-1005.

Kohls, M. (2010). Das demografische Verhalten der ausländischen Bevölkerung in Deutschland Analysen mit Daten des FDZ-RV. DRV-Schriften, 55, 149 - 173.

LALIVE, R. and ZweimÜLleR, J. (2009). How does parental leave affect fertility and return to work? evidence from two natural experiments. The Quarterly Journal of Economics, 124 (3), 1363-1402.

LARoqUE, G. and SALAniÉ, B. (2014). Identifying the response of fertility to financial incentives. Journal of Applied Econometrics, 29 (2), 314-332.

Milligan, K. (2005). Subsidizing the stork: New evidence on tax incentives and fertility. The Review of Economics and Statistics, 87 (3), 539-555. 
Moffitt, R. (1984). Profiles of fertility, labour supply and wages of married women: A complete life-cycle model. The Review of Economic Studies, 51 (2), 263-278.

Moffitt, R. A. (1998). The effect of welfare on marriage and fertility. In R. Moffitt (ed.), Welfare, the Family, and Reproductive Behavior: Research Perspectives, National Academies Press, pp. 50-97.

- and Wilhelm, M. (2000). Taxation and the Labor Supply - Decisions of the Affluent. Economics Working Paper Archive 414, The Johns Hopkins University,Department of Economics.

Nielsen, H. S., Sørensen, T. and Taber, C. (2010). Estimating the effect of student aid on college enrollment: Evidence from a government grant policy reform. American Economic Journal: Economic Policy, 2 (2), 185-215.

Riphahn, R. T. and Wynck, F. (2017). Fertility Effects of Child Benefits. IZA Discussion Paper 10757, Institute for the Study of Labor (IZA).

Rosenzweig, M. R. and Schultz, T. P. (1985). The demand for and supply of births: Fertility and its life cycle consequences. The American Economic Review, 75 (5), 992-1015.

Rothstein, J. and Rouse, C. E. (2011). Constrained after college: Student loans and early-career occupational choices. Journal of Public Economics, 95 (1-2), 149-163.

Sinn, H.-W. (2013). Das demographische Defizit, die Fakten, die Folgen, die Ursachen und die Politikimplikationen. Ifo Schnelldienst, 66 (21), 03-23.

Statistisches Bundesamt (2006). Erziehungsgeldstatistik 2006.

Statistisches Bundesamt (2016). Statistik der Geburten: Lebendgeborene (Anzahl).

Weber, B. and WeBER, E. (2013). Qualifikation und arbeitsmarkt, bildung ist der beste schutz vor arbeitslosigkeit. IAB Kurzbericht, 4.

Werding, M. and Hofmann, H. (2006). Die fiskalische Bilanz eines Kindes im deutschen Steuer- und Sozialsystem. Ifo Schnelldienst, 59 (02), 28-36.

Whittington, L. A., Alm, J. and Peters, H. E. (1990). Fertility and the personal exemption: Implicit pronatalist policy in the united states. The American Economic Review, 80 (3), 545-556.

Willis, R. J. (1973). A new approach to the economic theory of fertility behavior. Journal of Political Economy, 81 (2), S14-64. 


\section{Appendix}

\section{Appendix A: Benefit simulation and data coding}

\section{Benefit calculation}

Pre reform benefits: Prior to the reform, maternity leave payouts were means tested on household income during benefit receipt. I thus simulate a woman's pre reform entitlement if she gave birth to a child using 2006 Microcensus data on the current net income for the woman and her spouse, defined as either a husband or cohabitating partner. I restrict the sample to all women aged 20-44 in the survey year and approximate net yearly income based on the net monthly income variable, which is provided in 24 intervals. The pre reform eligibility thresholds were also based on net household income during benefit receipt, excluding income from public transfers. The income variable reported in the Microcensus includes social assistance and unemployment benefits, which I set to zero for individuals designated unemployed or inactive during the survey period. Because the number of very high earners is very small, I pool all observations for net income above 43,200 EUR. I simulate the woman's maximum potential benefits based her spouse's generated net labor income under the assumption that she has no labor income during benefit receipt. In calculating the potential entitlement, I apply the benefit eligibility rules to the spouse's current income, assigning the maximum benefit of 7,200 EUR (5,400 EUR for option 2) to women whose spouse earns under 16,800 EUR. If the spouse's net income falls between 16,800 and 22,200 EUR, the benefits range from a minimum of 1,980 EUR to a maximum of 7,200 EUR (2,700 EUR and 5,400 EUR for the short option), so I set the potential benefits equal to the midpoint of this benefit interval. Women whose spouse's net income lies between 22,200 EUR and 29,400 EUR would only have been eligible for a total benefit payment of 1,800 EUR over six months (for both options), while women with spousal net income above 29,400 EUR would have been ineligible for any maternity benefits. For women with no part-

ner in the household, family income during benefit receipt would lie below the income threshold, so I assign them the maximum benefit. Because some eligibility cutoffs fall into an income interval, I calculate the mean simulated benefit by applying the lower and upper brackets of the income interval, respectively.

I derive my baseline results by collapsing the simulated pre reform benefits (based on spousal income) by the respective earnings intervals of women aged 25-44. I then merge these simulated benefits with the pension data used in the main analysis. As an alternative, I simulate the pre birth earnings for five age group-specific education groups, which generates 15 distinct values for the simulated pre reform benefits. I then 
merge these values with the pension data by age and education.

Post reform benefits and net earnings: Because the post reform benefits are a direct function of women's labor earnings (independent of spousal earnings), I use a detailed maternity benefit calculator (http://www.familien-wegweiser.de/Elterngeldrechner) to generate the expected maximum benefit as the sum of monthly benefits over the total 12-month entitlement period based on women's gross yearly earnings (taken from the pension registry). Given the different tax class choices allowed couples under German joint taxation rules, I assume women to be taxed under tax class IV (equivalent to tax class I for singles), the commonest option for couples with relatively equal earnings. Calculating these benefits using alternative tax classes also has little effect on my estimates. For simplicity, I further assume that the women have no children, thereby eliminating any increase in calculated benefits by a small sibling premium. I calculate the net labor earnings for my estimation strategy using an implicit tax rate for gross yearly labor earnings, which is provided by the benefit calculator.

\section{Education coding}

The education groups, defined based on the German educational system, differentiate between low educated women without any postsecondary education (equivalent to category 1 and 2 of ISCED97), medium educated women who have completed an apprenticeship (equivalent to 3, 4 and 5b of ISCED97), and highly educated women with tertiary education (categories 5a and 6 of ISCED97). In a first step, I impute missing education by replacing the unknown value with the modal value for education in the woman's 3-digit occupational category. Furthermore, the modal education level of about $7 \%$ of the sample in the pension data is "unknown." Because these cases typically occur in low skilled occupations, often for part-time marginal jobs for which employers specify no education details, I include them in the low education group. 
Figure 1: Parental leave benefits in Germany -pre vs. post 2007 reform simulation for maximum amount of subsidies

\section{Part A: Total benefits in EUR}

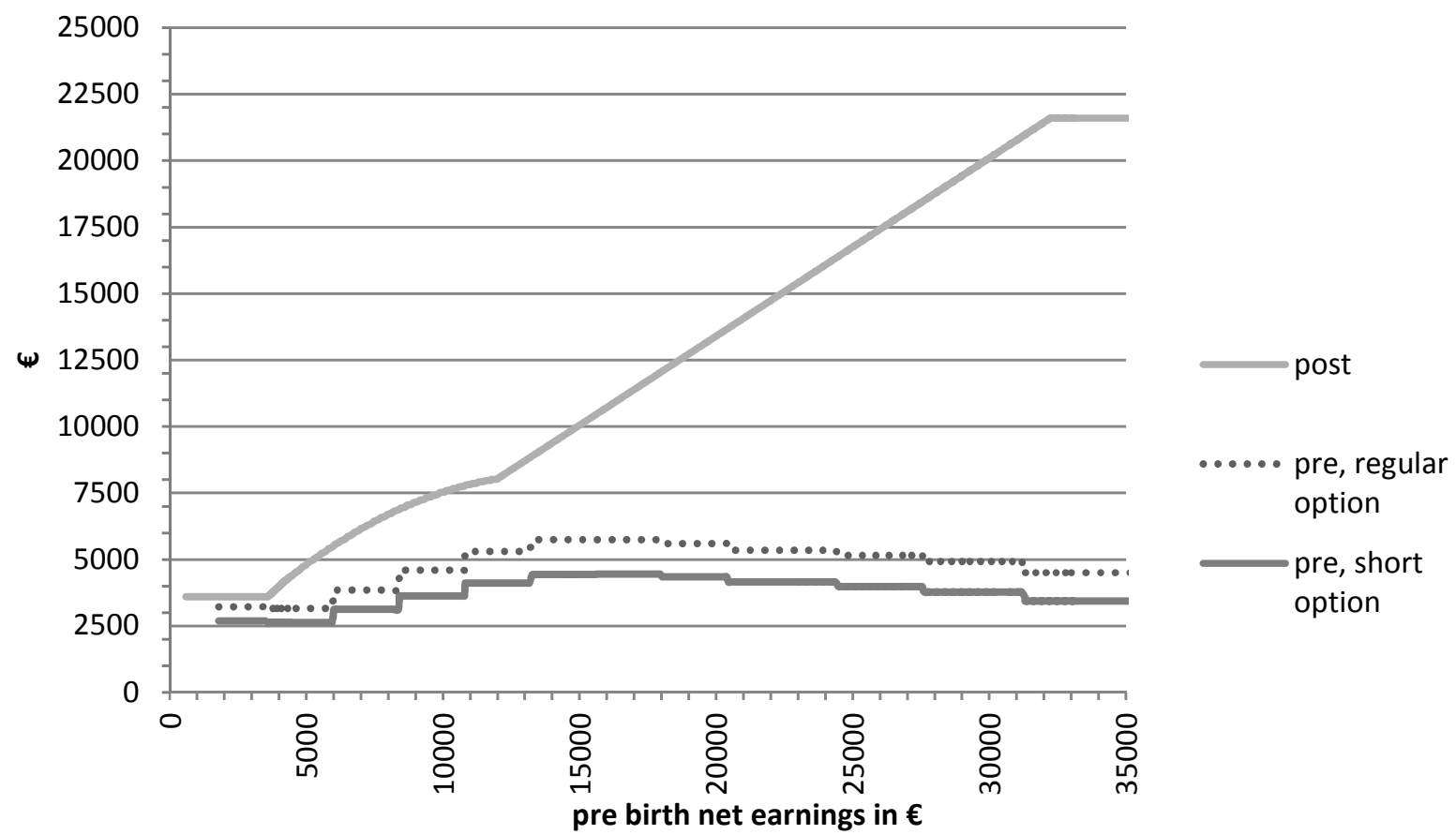

Part B: Replacement ratio of benefits in \% of net earnings

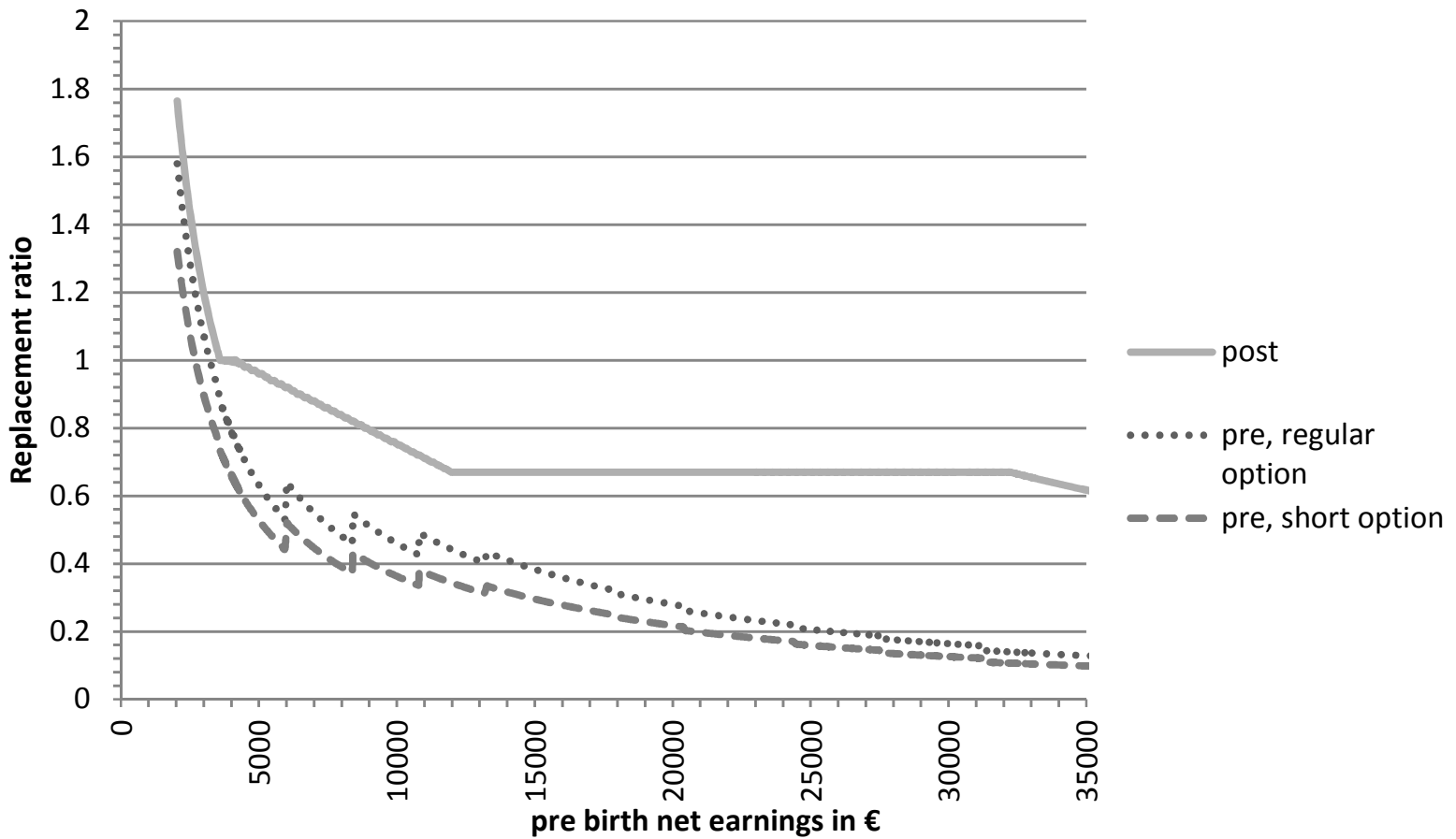

Notes: The graph in Part A shows maximum sum of benefits a woman would be entitled to against her yearly net earnings (in EUR), pre and post-reform. In Part B the sum of benefits is expressed as the replacement ratio of net yearly earnings. The post benefits are calculated via a benefit calculator for gross earnings. The pre-reform benefits for the 24-months option and the shorter 12-month-option, are simulated for discrete earnings brackets using the Microcensus 2006 (See Appendix A). 
Figure 2: Evolution of monthly births per 1000 women (aged 25-45), seasonality corrected

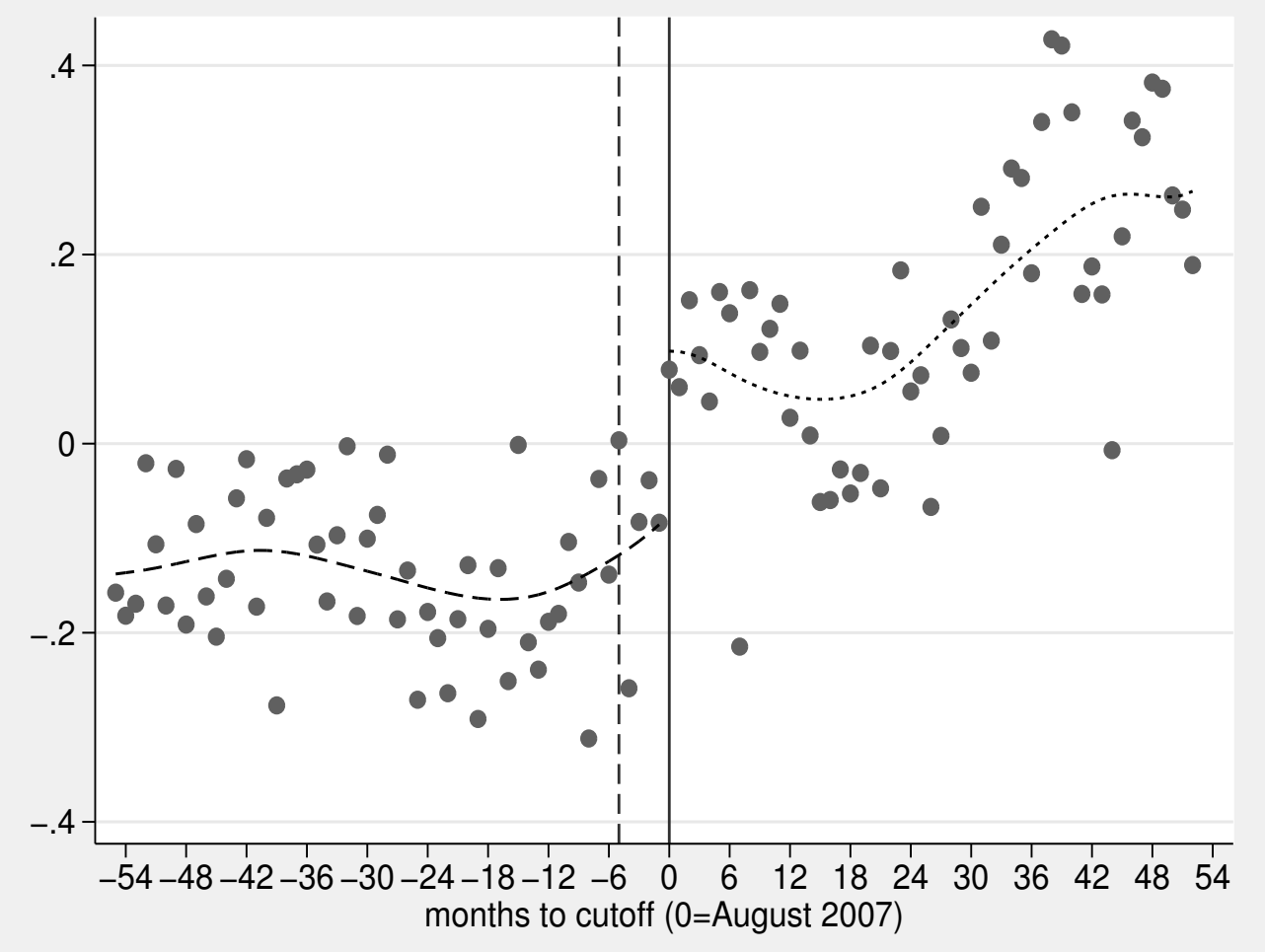

Notes : Lowess fit on both side of August 2007 (0 months to cutoff). The dashed line denotes March 2007, 9 months after announcement of the law. Data Source: Residual (month of birth adjusted) monthly livebirth per 1000 women aged 25-45 (on 31.12 of previous year), 2003-2011, vital statistics. 
Figure 3: Evolution birth probabilities vs. benefits for women above and below median earnings

Part A: Evolution of birth probabilities

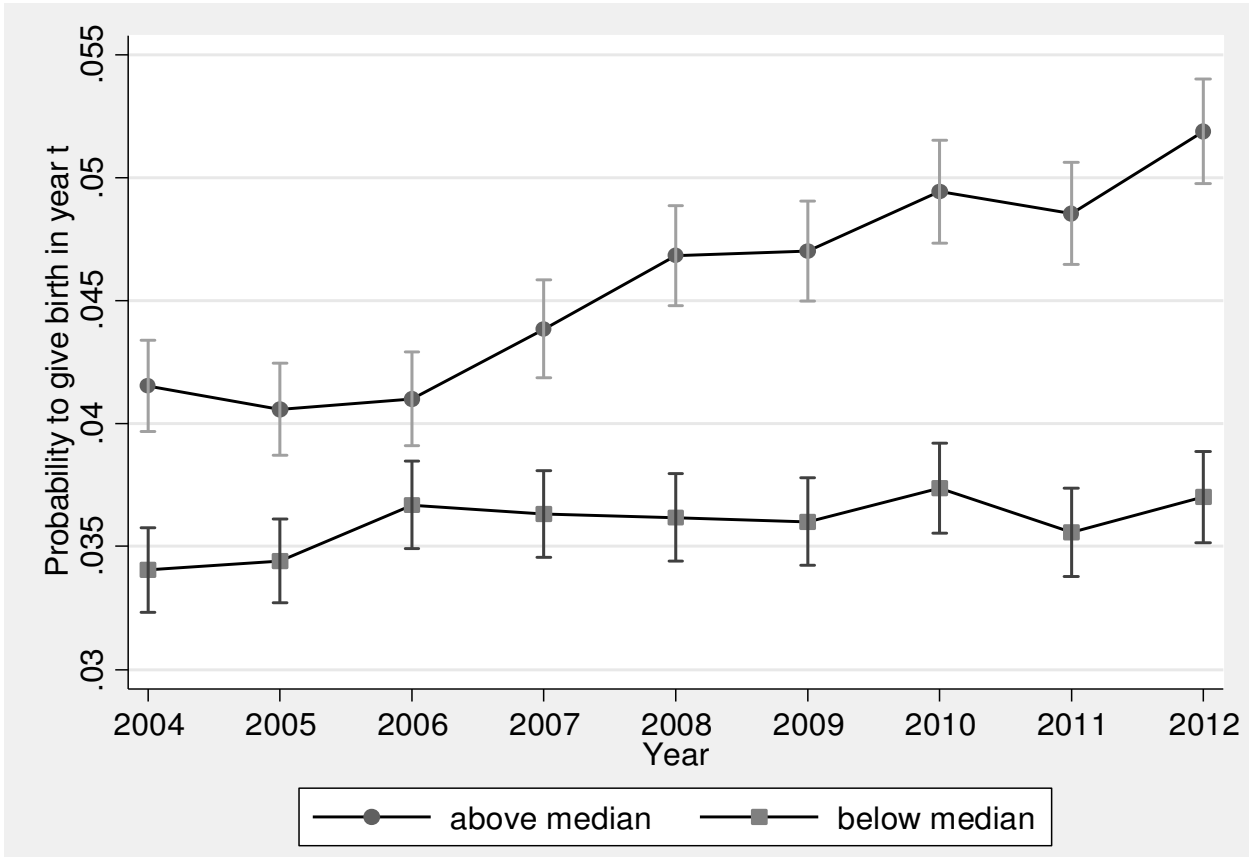

Part B: Increase in benefits post-reform

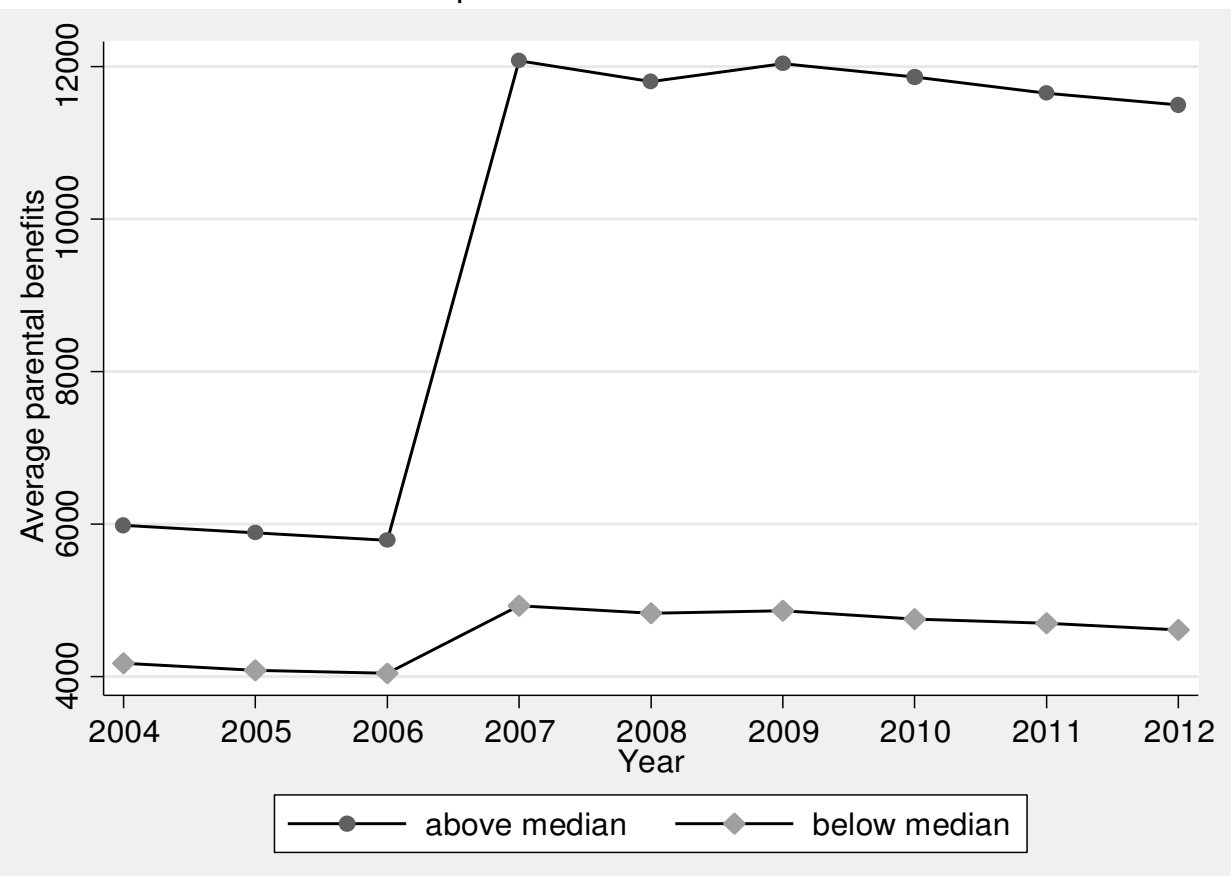

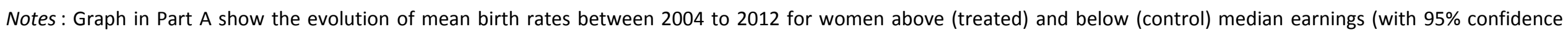

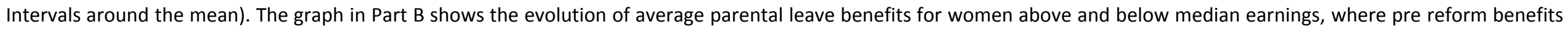
are defined by a woman's income. Data Source: pension registry data (AKVS) 2004-2012, Microcensus 2006 for pre-reform benefit simulation. 


\section{Figure 4: Evolution birth probabilities vs. benefits across education groups}

Part A: Evolution of birth probabilities

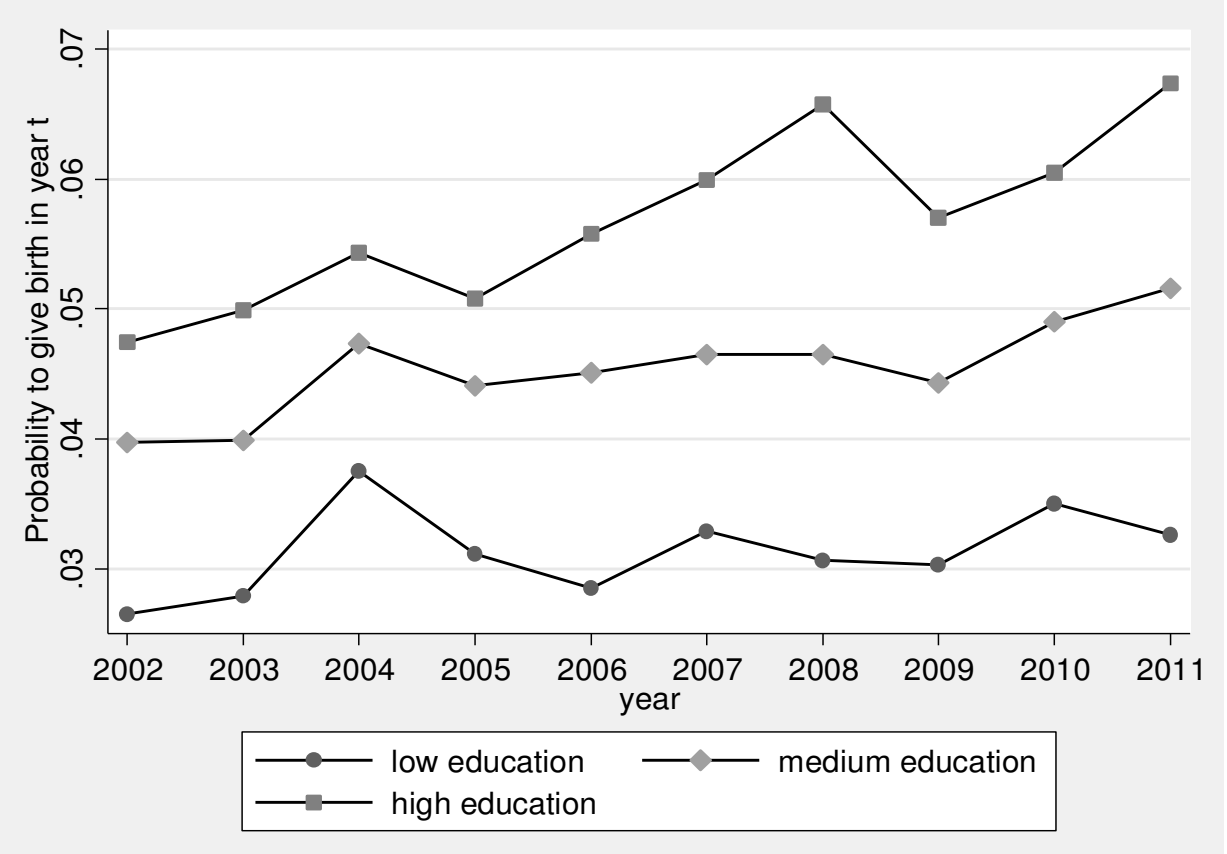

Part B: Increase in benefits post-reform

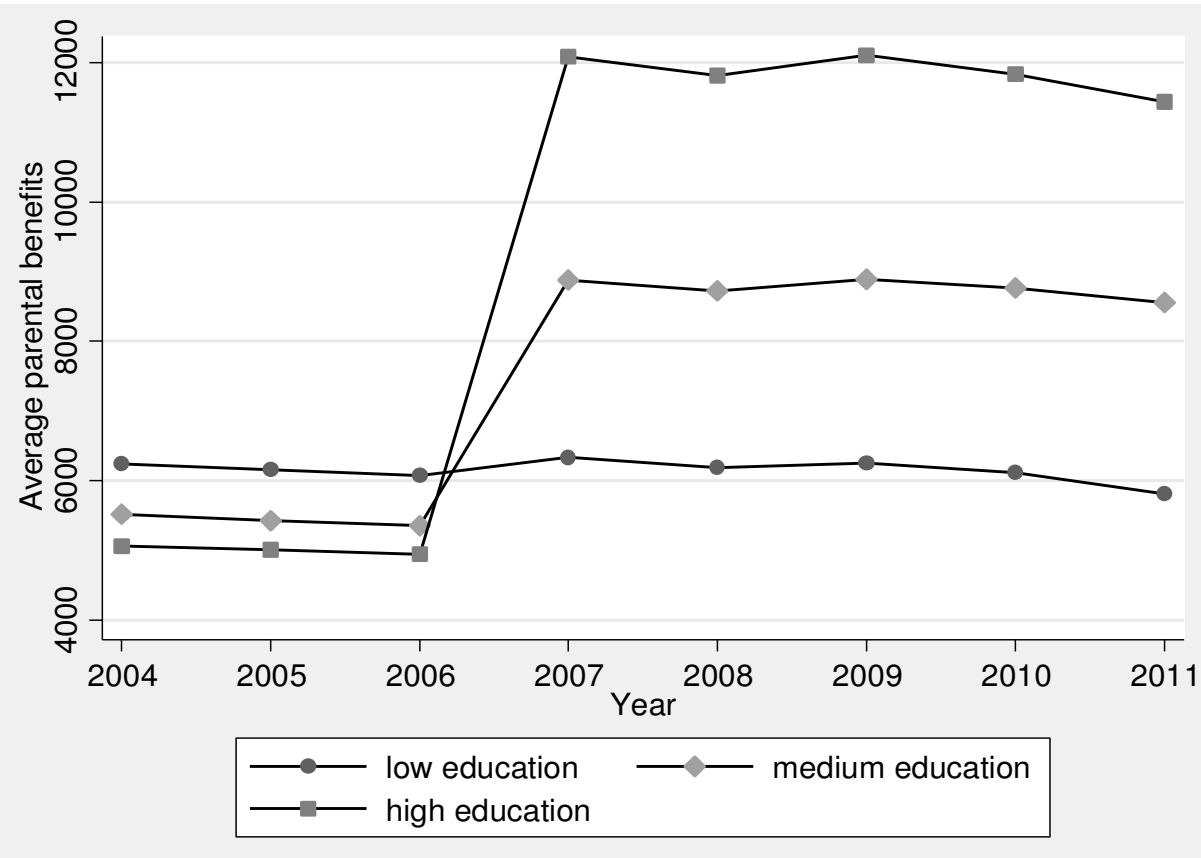

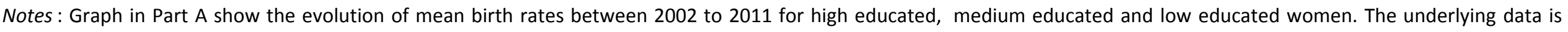

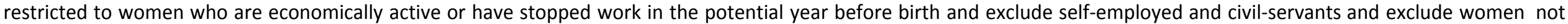

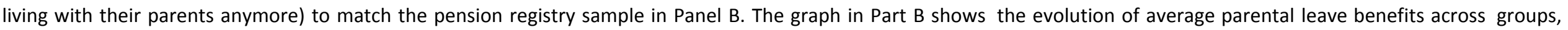
where pre-reform benefits are defined by a women's age and education. Data Source: SUF Microcensus 2003-2012, Microcensus 2006 for pre-reform benefit simulation. 
Figure 5: Increase fertility vs. benefits post reform along income distribution

Part A: Increase in birth probability post-reform

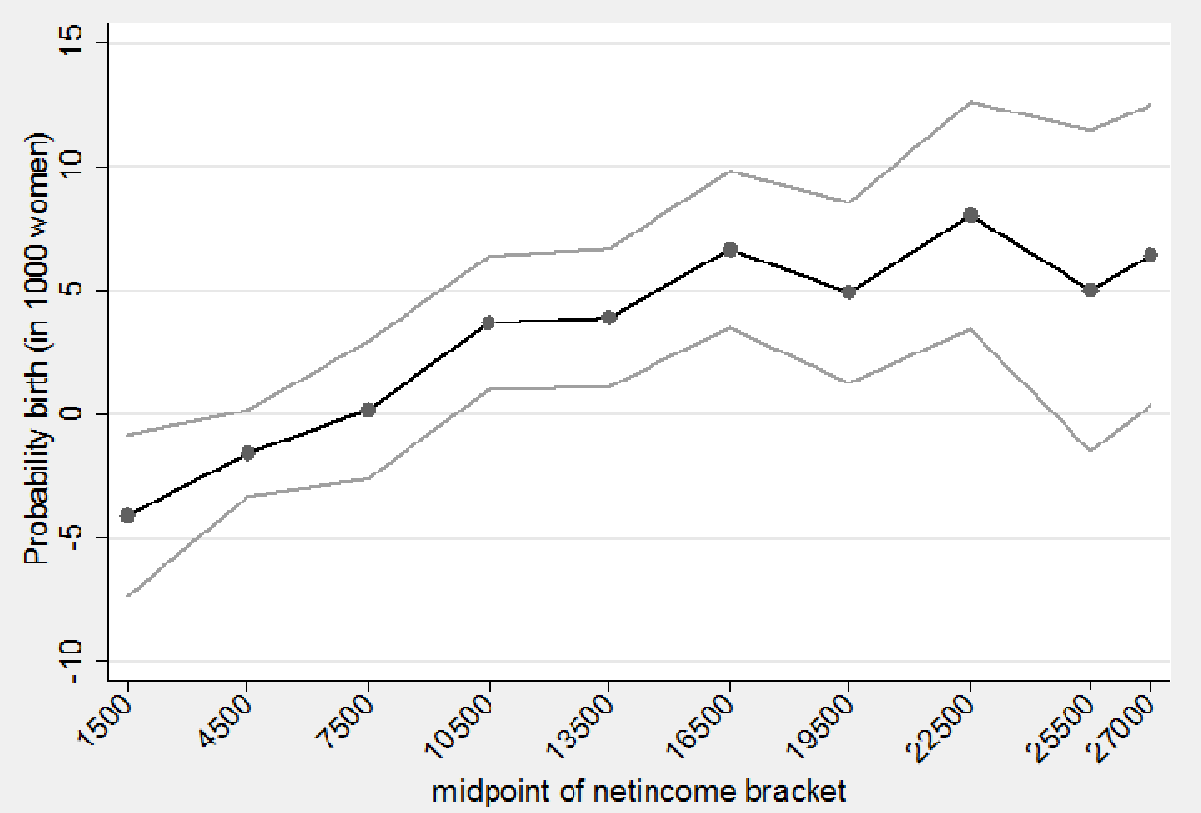

Part B: Increase in benefits post-reform

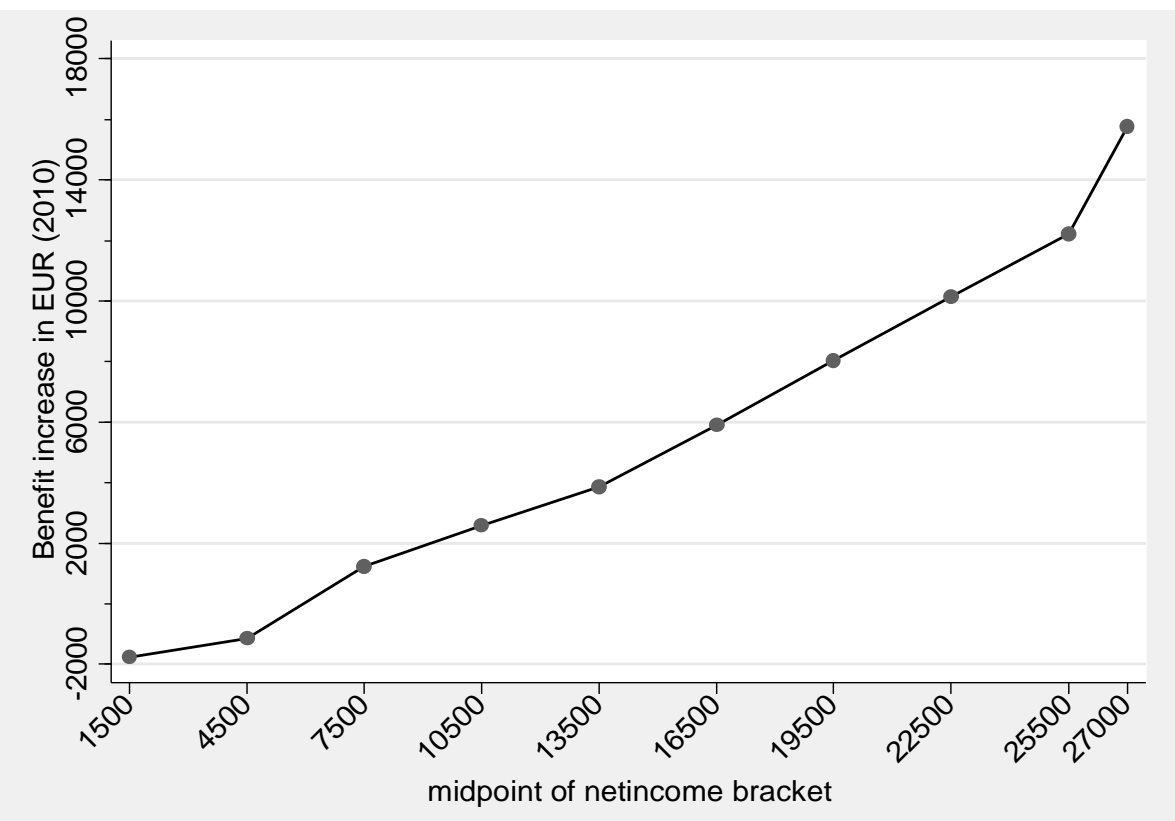

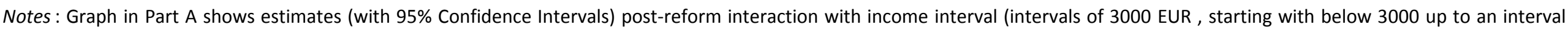

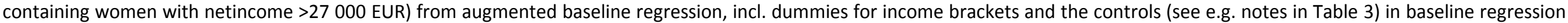

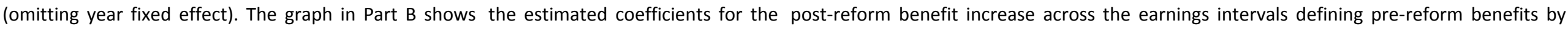
women's income. Data Source: pension registry data (AKVS) 2004-2012, Microcensus 2006 for pre-reform benefit simulation. 


\section{Panel A: Total fertility rates across countries}

\begin{tabular}{cc}
\hline Germany (2006) & 1.33 \\
Italy (2011) & 1.4 \\
US (2011) & 1.89 \\
UK (2011) & 1.98 \\
Sweden (2009) & 1.94 \\
\hline
\end{tabular}

\section{Panel B: Fertility indicators by education level (completed fertility)}

\begin{tabular}{lcccc}
\hline & \multicolumn{2}{c}{ Average number of children per } & \multicolumn{2}{c}{$\%$ childless } \\
& low & homan & low & high \\
\hline US & 2.56 & 1.81 & $12 \%$ & $20 \%$ \\
UK & 2 & 1.4 & $15 \%$ & $30 \%$ \\
Germany & 2.06 & 1.31 & $18 \%$ & $31 \%$ \\
Sweden & 2.1 & 1.8 & $14 \%$ & $18 \%$ \\
\hline
\end{tabular}

Notes: Panel A reports total fertility rates across various country, information is based on Worldbank Development indicators and information by national Statistical offices. In Panel B I report completed fertility rates for cohorts born around 1965 for women without a secondary schooling degree (or for UK and Sweden for women who only completed the minimum compulsory schooling) and women with tertiary education (college degree for US). Information is based on U.S. Census Bureau (2010), Ratcliff and Smith (2006) for the UK, Bujard (2012) and Statistisches Bundesamt (2010) for Germany and Boschini et al. (2011) for Sweden. 
Table 2: Overview over changes in parental leave benefit system

\begin{tabular}{|c|c|c|c|}
\hline & \multicolumn{2}{|c|}{ pre-2007 benefits (Erziehungsgeld) } & \multirow[t]{2}{*}{ post-2007 benefits (Elterngeld) } \\
\hline & Option 1 & Option 2 & \\
\hline Monthly benefits & 300 EUR & 450 EUR & $\begin{array}{l}\text { ca. } 67 \% \text { of pre-birth net earnings; } \\
\text { min. } 300 \text { EUR , max. } 1800 \text { EUR. } \\
\text { Mothers without employment history } \\
\text { entitled to } 300 \text { EUR }\end{array}$ \\
\hline Means testing & \multicolumn{2}{|c|}{ yes, family income during receipt (see Notes) } & no \\
\hline Max. duration & 24 months & 12 months & 12 months (average 11.7 months) \\
\hline Total max. benefits & 7,200 EUR & 5,400 EUR & $3,600-21,600$ EUR \\
\hline Proportion covered & $65 \%(2006)$ & $10 \%(2006)$ & close to $100 \%$ \\
\hline Average paid $(06 / 07)$ & \multicolumn{2}{|c|}{$3,850-4,440$ EUR (2006) } & $\begin{array}{l}\text { 7,080 EUR (previously employed: } \\
\text { 10,128 EUR (2008)) }\end{array}$ \\
\hline
\end{tabular}

Requirements not working more than $30 \mathrm{~h}$ during transfer receipt

Notes: Information on average paid and proportion covered is calculated on statistics on Elterngeld and Erziehungsgeld provided by the German Statistical office. Note that post 2007, two additional months of benefit entitlement are reserved for the other parent. Pre 2007, the income threshold (after deductibles) was 30,000 EUR for couples (23,000 EUR for single parents). Benefits were restricted to a duration of 6 months for those with an income threshold above around 21,000 EUR (and below 30,000 EUR). The income referred to the household income during benefit receipt. See Kluve and Tamm (2013) for further reform details. 
Table 3: Descriptive Statistics

\begin{tabular}{lr}
\hline Panel A: Individual characteristics & \\
\hline $\begin{array}{l}\text { Outcome variable } \\
\text { Probability to give birth in a given year }\end{array}$ & 0.041 \\
Parental leave benefits & \\
Pre reform (2010 EUR) & 4986.87 \\
(std. dev) & $(1173.661)$ \\
Post reform (2010 EUR) & 8280.25 \\
(std. dev) & $(4472.321)$ \\
& \\
Selected covariates & \\
Age & 33.37 \\
Age when giving birth & 30.67 \\
German nationality & 0.91 \\
Education (based on Microcensus) & \\
Share low-educated & 0.24 \\
Share medium-educated & 0.62 \\
Share high-educated & 0.15
\end{tabular}

Percentiles of earnings distribution (in EUR)

$\begin{array}{lcc} & \text { net } & \text { gross } \\ \text { 10th } & 3,262 & 3,262 \\ \text { 25th } & 3,934 & 4,933 \\ 50 \text { th } & 10,114 & 14,874 \\ \text { 75th } & 16,232 & 25,903 \\ 90 \text { th } & 21,540 & 36,091 \\ 95 \text { th } & 25,131 & 43,468\end{array}$

Panel B: Parity information from Microcensus (all women)

$\begin{array}{ll}\text { Woman does not have a child } & 0.39 \\ \text { Woman is mother of one child } & 0.27 \\ \text { Woman is mother of two children } & 0.25 \\ \text { Woman is mother of three or more children } & 0.09\end{array}$

Notes: Panel A reports sample means of the probability to give birth in a given year (outcome variable) and the average benefits a woman could receive in the pre-reform and post-reform period (standard deviation in parantheses). It further reports selected individual charactertics of women as well as the percentile of the distribution of earnings in the preceding year in EUR, both in gross and net terms. Information of education of women is based on the Micocensus sample. Panel B reports information on the number of existing children in the household for the sample of all women aged 21-44 of the Microcensus.

Source: Panel A: SUF AKVS 2004-2012 (own calculations based on estimation sample), Calculation of pre-reform benefits as outlined in Appendix B. Information on education based on SUF Microcensus 2005-2012. Panel B: SUF Microcensus 2005-2012. 


above median* post 2007
$N=644,981$
above 90 th percentile*post 2007
$N=128,678$

50th-75th percentile* post2007

$N=333,030$

in \% terms of pre reform mean

(41.06 (above 50th), 44.48 (90th) 38.61 (50th-75th))

$7.235^{* * *}$

(0.983)

no controls
$7.880^{* * *}$
$(0.990)$

(0.990)
Compare top 10th vs. Bottom 10th percentile add earnings
Placebo reform in 2006 (pre-reform period 20042006)

$\mathrm{N}$

644,981

\section{$-0.984$}

$12.029 * * *$

(2.369)

Notes: All regressions show estimates for a linear probability model of giving birth in $\mathrm{t}$ and are estimated for women aged 21-44 with positive earnings in $\mathrm{t}-1$ for years 2004-2006 and 2008-2012. The interaction with post 2007 and earnings dummies tests for differential time trends post reform with respect to women below that earnings threshold (control group). In (1)-(3) the treatment group consists of women above median earnings (control group: below median earnings). In (4) the treatment group consists of women with earnings above the 90th percentile (treatment group: below 10th percentile) and in (5) of women with earnings between median and 75th percentile (control: 25th-median earnings). In (6) I estimate the effect for a placebo reform in 2006 and restrict the sample period to $2004-2006$ $(\mathrm{N}=253,668)$. I control for treatment group indicators. I have further controlled for year dummies, region (Länder) dummies, age dummies and separate age dummies for tertiary educated women, a dummy for German nationality, education dummies, social benefit and vocational training status in $\mathrm{t}-1$ as well dummies whether the woman has had a child in $\mathrm{t}-1$ and $\mathrm{t}-2$. In Specification (2) I drop all control variables and in (3) I additionally account for earnings and its square in $\mathrm{t}-1$. Robust standard errors reported in brackets. ${ }^{*}$ indicates significance at $10 \%, * *$ indicates significance at $5 \%, * * *$ indicates significance at $1 \%$ level.

Source: SUF (1\%) AKVS 2004-2012. 
Table 5: Linear probability model (birth in 1000 women) allowing for reform effect to differ by education

\section{(1)}

$$
\text { (4) }
$$

match pension registry sample

Placebo chec

(7)

lacebo reform

also exclude women

Baseline

account for

restrict to

who are civil

placebo reform for 2004, match

equation 2

without controls number of children

women

employed

2006 births)

sample

\section{medium education*post2007 \\ in \% of pre}

0.597

0.813

(1.389)

(1.402)

-0.26
$(1.387)$

2.419

(1.477)

$2.781^{*}$

$(1.527)$

2.422

(1.480)

0.453

tertiary education* post2007

$\begin{array}{cccc}8.469 * * * & 7.065^{* * *} & 7.395^{* * *} & 11.173^{* * *} \\ (2.114) & (2.131) & (2.106) & (2.206)\end{array}$

\section{$7 \%$}

$11.359 * * *$

(2.491)

2.91

1.434

in \% of pre reform mean (57.61 (1) and

$15 \%$

$22 \%$

\begin{tabular}{lc}
$50.83(5))$ & $15 \%$ \\
\hline $\mathrm{N}$ & 516,418
\end{tabular}

516,418

515,765

401,056

357,789

460,975

342,592

Notes: All regressions show estimates for a linear probability model of giving birth and are estimated for women aged 21-44, over birth years 2004-2006 and $2008-2011$ (survey years 2005-2012). The interaction with post 2007 and education tests for differential time trends post reform with respect to low skilled women (control group). I control for education group dummies (treatment group indicators) as well as year dummies. I have further controlled for region (Länder) dummies, age dummies and separate age dummies for tertiary educated women, a dummy for German nationality and whether the woman was born in Germany. In (2) I drop the individual level control variables. In (3) I account for the number of children in total and the age composition of existing children (below 3 as well as 3-5). In (4) I restrict the sample to women who are active or stopped working the year of giving birth and in (5) additionally exclude women who are currently civil servants or selfemployed. I estimate a placebo reform for 2004 on pre-reform data (2001-2006) for all women (6) and restricting the sample to women are active or stopped working the year of potential birth in (7). Robust standard errors reported in brackets. * indicates significance at $10 \%$, ** indicates significance at $5 \%, * * *$ indicates significance at $1 \%$ level.

Source : SUF Microcensus 2005-2012. 
Table 6: Linear probability model (birth in 1000 women) for benefit in EUR- Baseline and Robustness

$(1)$
(3)

(4)

(6)

(7)

(8)

alternative definition of pre-

reform benefits

$\underline{\text { IV estimate }}$

interact control reform in 2006

second order function with (restrict to 2004-

polynomial in education group 2006 pre reform Budget option education pre education-year

(estimation

equation 3)

Effect of total expected benefits in 1000 EUR

$0.783^{* * *}$

(0.130)

$0.812 * * *$

real net earnings

Effect in \% of mean births pre (38.05)

First stage F-statistic

First stage: Partial R2

$2.1 \%$

(0.131)

$0.780 * *$

(0.127)

dummies

years)

$0.763 * * *$

$-0.083$

(0.225)

(0.131) pre 2007

group by

IV: Instrument benefits with interactions

644,981

644,981

644,981

644,981

253,668

629,691

629,691

$0.768 * * * \quad 1.096 * * *$

(0.111) (0.371)

$2.9 \%$

4859.74

0.111

644,981

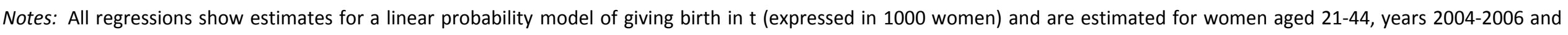

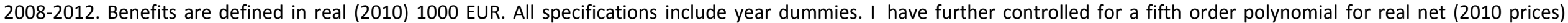

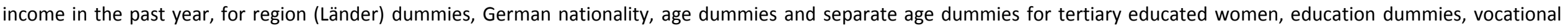

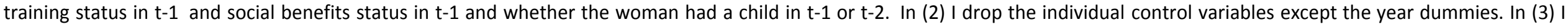

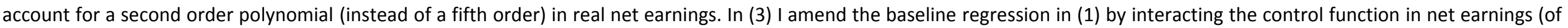

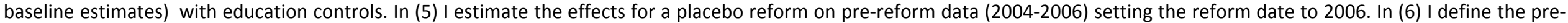

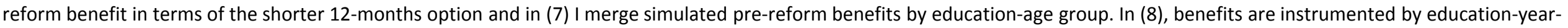
interactions. Robust standard errors reported in brackets. ${ }^{*}$ indicates significance at $10 \%, * *$ indicates significance at $5 \%, * * *$ indicates significance at $1 \%$ level.

Source: SUF (1\%) AKVS 2004-2012, women with positive earnings in $\mathrm{t}-1$. 
Table 7: Robustness of baseline benefits estimates to function form

Effect on probability of giving birth in t (births per 1000 women)

\section{A: Benefits expressed as replacement ratio of net earnings}

Effects of increase in replacement rate in 1\%-point

Effect of $10 \%$ point increase in replacement rate by... in \% of mean births pre reform (38.05)

\section{B: Benefits expressed in log benefits}

Effect of increase in benefits by $100 \%$

Interpretation of estimate: 10\%-point increase in expected benefits increases births by 0.71 (per 1000)

Implied percentage change of $10 \%$ increase (in \% of pre reform mean)

Notes: All regressions show estimates for a linear probability model of giving birth in $t$ (expressed in 1000 women) and are estimated for women aged 25-44, years 2004-2006 and 2008-2012. in Panel A I define benefits as a replacement rate in percentage terms of net earnings in t-1. To avoid large outliers, I restrict the sample in Panel A to women with netincomes larger than 2000 EUR in $\mathrm{t}-1(\mathrm{~N}=607,634)$. In Panel B I use log benefits instead of benefits in levels. I have further controlled for a fifth order polynomial for real net (2010) earnings in t-1 (polynomial in log real net earnings in B) , for Länder dummies, German nationality, education dummies, a dummy for vocationa training status in $\mathrm{t}-1$, age dummies and separate age dummies for tertiary educated women, year dummies and social benefits status in t- 1 and whether the woman had a child in $\mathrm{t}-1$ or $\mathrm{t}-2$. Robust standard errors reported in brackets. ${ }^{*}$ indicates significance at $10 \%, * *$ indicates significance at $5 \%, * * *$ indicates significance at $1 \%$ level.

Source: SUF (1\%) AKVS 2004-2012, women with positive earnings in t-1. 
Table 8: Results by age group - linear probability model (birth in 1000 women) for benefit in EUR

\begin{tabular}{|c|c|c|c|c|c|}
\hline & (1) & $(2)$ & (3) & (4) & (5) \\
\hline & Age $20-24$ & Age $25-29$ & Age $30-34$ & Age $35-39$ & Age $40-44$ \\
\hline Pre-reform mean of probabiliy of having child & 30.49 & 67.34 & 72.27 & 32.6 & 5.17 \\
\hline \multicolumn{6}{|l|}{ Panel A: All women } \\
\hline Effect of total expected benefits in 1000 EUR & $\begin{array}{c}0.563 \\
(0.429)\end{array}$ & $\begin{array}{l}0.893 * * \\
(0.393)\end{array}$ & $\begin{array}{c}0.52 \\
(0.391)\end{array}$ & $\begin{array}{c}1.087^{* * *} \\
(0.282)\end{array}$ & $\begin{array}{l}0.250 * * \\
(0.108)\end{array}$ \\
\hline $\begin{array}{l}\text { Effect of increase in benefits by } 1000 \text { EUR in \% of pre } \\
\text { reform mean }\end{array}$ & & $1.3 \%$ & & $6.1 \%$ & $4.8 \%$ \\
\hline $\mathrm{N}$ & 118,846 & 123,025 & 115,011 & 135,335 & 173,782 \\
\hline
\end{tabular}

Notes: All regressions show estimates from separate regressions for various age groups $(20-24,25-29,30-34,35-49$, 40-44) of the linear probability model of giving birth in $t$ (expressed in 1000 women) and are estimated for women aged 25-44, years 2004-2006 and 2008-2012. In Panel A, I estimate on the sample of all women with positive earnings in $\mathrm{t}-1$. In Panel B, I exclude women with earnings in t-1 above the 90th percentile of net earnings for each respective age group. Benefits are defined in real (2010) 1000 EUR. I have further controlled for a fifth order polynomial for real net (2010) income in past year, for Länder dummies, German nationality, age dummies and separate age dummies for tertiary educated women, education dummies, year dummies and social benefits status in $\mathrm{t}-1$ and whether the woman had a child in $\mathrm{t}-1$ or $\mathrm{t}-2$. Robust standard errors reported in brackets. ${ }^{*}$ indicates significance at $10 \%, * *$ indicates significance at $5 \%, * * *$ indicates significance at $1 \%$ level.

Source: SUF (1\%) AKVS 2004-2012, women with positive earnings in t-1. 
Figure A1: Evolution birth probabilities for altenative treatment-control groups

Part A: For women in the top vs. bottom 10th percentile

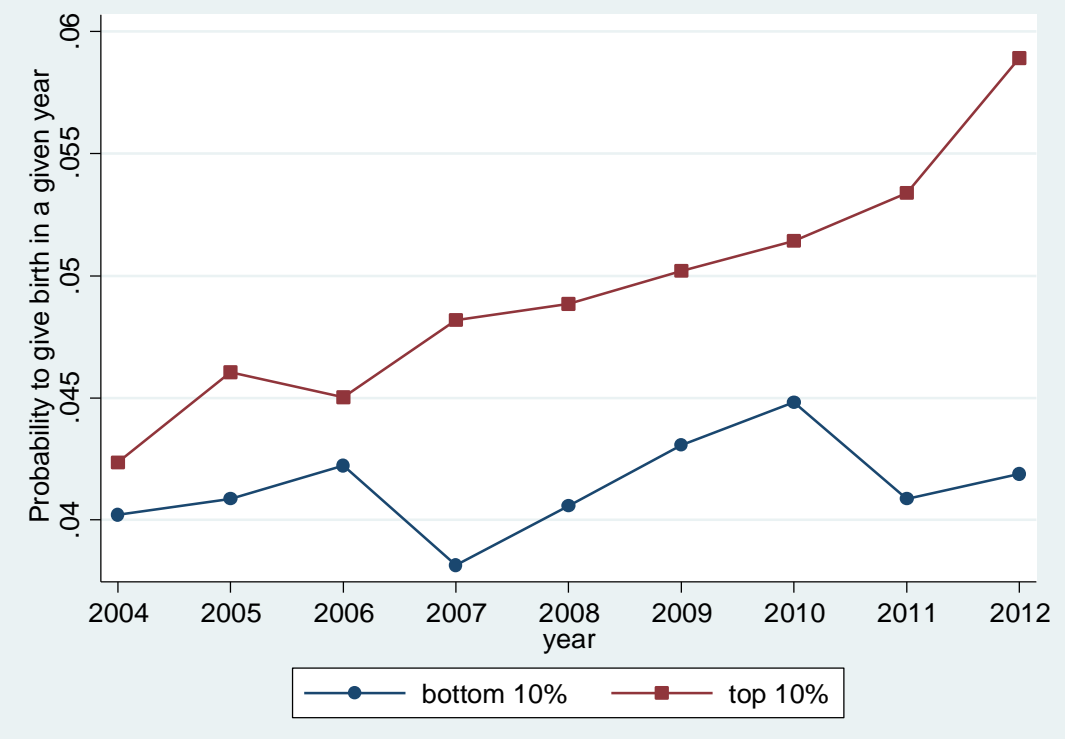

Part B: Compare 25th-50th vs. 50th-75th percentile

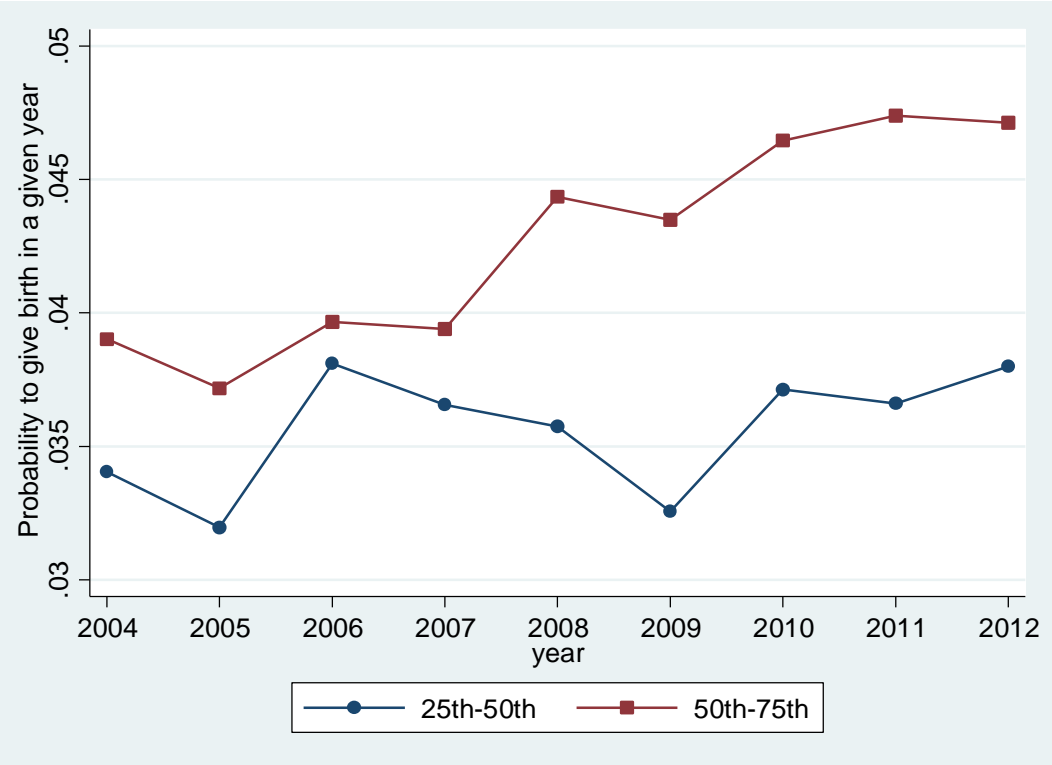

Notes: Part A shows the evolution of mean birth rates between 2004 to 2012 for women in the top decile (treated) vs. the bottom decile (control) of the earnings distribution (with $95 \%$ confidence Intervals around the mean). Part B shows the evolution of mean birth rates between 2004 to 2012 for women in the interquartile range (50th-75th percentile vs. 25 th50th percentile) of the earnings distribution (with 95\% confidence Intervals around the mean). Data Source: SUF (1\%) AKVS 2004-2012, women with positive earnings in t-1. 
Table A1: Linear probability model (birth in 1000 women) allowing for reform effect to differ by education - Results using pension registry data (AKVS 2004-2012)

\begin{tabular}{|c|c|c|c|}
\hline & $\begin{array}{c}\text { (1) } \\
\text { Baseline } \\
\text { (estimation } \\
\text { equation 1) }\end{array}$ & $\begin{array}{l}\text { without control } \\
\text { variables }\end{array}$ & $\begin{array}{l}(2) \\
\text { account for social } \\
\text { benefit status, } \\
\text { polynomial in real } \\
\text { earnings }\end{array}$ \\
\hline medium education*post2007 & $\begin{array}{c}3.148 * * * \\
(1.100)\end{array}$ & $\begin{array}{l}2.542 * * \\
(1.107)\end{array}$ & $\begin{array}{c}3.365^{* * *} \\
(1.099)\end{array}$ \\
\hline $\begin{array}{l}\text { in \% terms of pre reform mean (39.87) } \\
\text { tertiary education*post } 2007\end{array}$ & $\begin{array}{c}8 \% \\
6.363 * * * \\
(2.287)\end{array}$ & $\begin{array}{l}4.498 * * \\
(2.293)\end{array}$ & $\begin{array}{c}6.678 * * * \\
(2.286)\end{array}$ \\
\hline in \% terms of pre reform mean (48.85) & $13 \%$ & & \\
\hline $\mathrm{N}$ & 644,981 & 644,981 & 644,981 \\
\hline
\end{tabular}

Notes: All regressions show estimates for a linear probability model of giving birth in $\mathrm{t}$ and are estimated for women aged 21-44 with positive earnings in t-1 for years 2004-2006 and 2008-2012. The interaction with post 2007 and education tests for differential time trends post reform with respect to low skilled women (control group) . I control for education group dummies (treatment group indicators). I have further controlled for year dummies, region (Länder) dummies, age dummies and separate age dummies for tertiary educated women, a dummy for German nationality as well dummies whether the woman has had a child in t-1 and t-2 and vocational training status in t-1. In specification (2) I omit all control variables. In specification (3) I account for earnings and its square in $\mathrm{t}-1$ and social benefits status. Robust standard errors reported in brackets. ${ }^{*}$ indicates significance at $10 \%, * *$ indicates significance at $5 \%, * * *$ indicates significance at $1 \%$ level.

Source: SUF (1\%) AKVS 2004-2012. 
Table A2: Checks on employment adjustment of mothers to reform

Panel A: Adjustments in earnings and hours (intensive margin)- using pension registry data

Treatment group: Mothers in t, control group: Older women aged 46-59.

(1)

Dummy for change in hours

between $\mathrm{t}$ and $\mathrm{t}-\mathrm{1}$ for Changes in earnings in EUR

women working part time in per day worked between $t$

$\mathrm{t}-1$

and $\mathrm{t}-1$

\begin{tabular}{lcc} 
& $\mathrm{t}-1$ & and t-1 \\
\hline \multirow{2}{*}{ gave birth in $\mathrm{t}^{*}$ post2007 } & 0.002 & 0.074 \\
$\mathrm{~N}$ & $(0.007)$ & $(0.304)$ \\
& 159,554 & 356,886 \\
\hline
\end{tabular}

Panel B: Differential Changes in labor market status (extensive margin) using Microcensus data

Treatment group: Mothers in t, control group: Older women: 46-59.

Outcome: Mother is active in labor market

gave birth in $t^{*}$ post 2007

$\mathrm{N}$ 378,686

Note: All regression show differences-in-differences estimates on various labor market outcomes, comparing women above age 20 who gave birth in year $t$ (treatment) and older women (ages 46-59). Panel A is based on the pension registry data. The outcome in column (1) is an increase in hours between year t and t-1 for women previously working part-time in t-1 (measured by a binary indicator which takes the value one when a woman changed from small to large part-time or part-time to full-time). Results in column (1) are restricted to years 2004-2010, as the coding of the part-time variable changed in 2011. The outcome in (2) are changes in daily earnings between $\mathrm{t}-1$ and $\mathrm{t}$ for all women who were previously employed. Panel $B$ is based on data from the German Microcensus and measures whether a woman is economically active, measured by a dummy for being either active in year t or having stopped work in the previous year. The interaction post 2007 and the indicator for giving birth tests for differential time trends in labor market outcomes post reform of new mothers with respect to older women (control).

Source: Panel A: SUF (1\%) AKVS 2004-2012, Panel B: SUF Microcensus 2005-2012. 
Table A3: Check on employment adjustment of women of childbearing age as response to reform

Treatment group: Younger women aged 21-34, control group: Older women aged 46-59.

(1)

Outcome: Woman is working

young woman*post 2007

$-0.017$

(0.0024)

$\mathrm{N}$

624,530

Note: The regression shows differences-in-differences estimates on labor market participation, comparing younger women of childbearing age (age 21-34, treatment) and older women (age 46-59). The regression is based on data from the German Microcensus and measures whether a woman is working in a given year. The interaction post 2007 with the indicator for young woman tests for differential time trends in labor market participation post reform of women of childbearing age with respect to older women (control).

Source: SUF Microcensus 2005-2012. 
Table A4: Results by birth order- Linear probability model (birth in 1000 women) allowing for reform effect to differ by education - using German Microcensus (births 2004-2011)

Panel A: Probability for first or second or higher order birth (births per 1000 women)- all age groups

(1)

\begin{tabular}{lccc} 
& RV sample (active & $\begin{array}{c}\text { Mean birth rate pre } \\
\text { reform (all women) }\end{array}$ \\
tertiary education* post2007 & $9.767^{* * *}$ & $12.020^{* * *}$ & 56.92 \\
& $(2.683)$ & $(2.742)$ & \\
& -1.349 & 2.702 & 95.64 \\
tertiary education* post2007* second births & $(5.165)$ & $(5.377)$ & \\
tertiary education* post2007*third (and higher order) & $-6.818^{* *}$ & $-7.402 * *$ & 25.83 \\
births & $(3.426)$ & $(3.476)$ & \\
$\mathrm{N}$ & 515,765 & 400,716 & \\
\hline
\end{tabular}

Panel B: Heterogeneous effects on completed fertility - birth order for women aged 40-44

\begin{tabular}{|c|c|c|c|}
\hline \multirow{5}{*}{ tertiary education*post2007 } & (1) & $(2)$ & \\
\hline & All women & $\begin{array}{c}\text { RV sample (active } \\
\text { before) }\end{array}$ & $\begin{array}{c}\text { Mean birth rate pre } \\
\text { reform }\end{array}$ \\
\hline & 6.657 & 6.321 & 24.7 \\
\hline & $(4.626)$ & (4.667) & \\
\hline & $13.488 * *$ & $11.618^{*}$ & 27.94 \\
\hline tertiary education*post $2007 *$ second births & $(6.788)$ & $(6.903)$ & \\
\hline $\mathrm{N}$ & 74,128 & 63,370 & \\
\hline
\end{tabular}

Notes: All regressions show estimates for a linear probability model of giving birth in $t$ and are estimated for years 20042006 and 2008-2012. I only show results for tertiary educated women. In Panel A I look at probabilities to have a first birth, second or third (or higher) for women aged 20-45 estimating a model with additional interactions of second as well as third and higher order with the post 2007 dummy to test for heterogeneous reform responses for the second and higher order births. In Panel B I restrict my sample to women at the end of their fertile cycle, age 40-44, to investigate the effects on completed fertility along the extensive (first birth) and intensive margin (second birth). In column (1), I include all women observed in the Microcensus. In column (2), I restrict the sample to women who have been in employment to match the sample composition of the pension registry data. The interaction with post 2007 and education tests for differential time trends post reform for first births with respect to low skilled women (control group, captured by post 2007 dummy). I have further controlled for Länder dummies, age dummies and separate age dummies for tertiary educated women, a dummy for German nationality and whether the woman has been born in Germany as well as year dummies. I additionally account for dummies measuring that the woman has one or more than one children as well as age dummies of existing children. Robust standard errors reported in brackets. ${ }^{*}$ indicates significance at $10 \%, * *$ indicates significance at $5 \%, * * *$ indicates significance at $1 \%$ level.

Source : SUF Microcensus 2005-2012. 